\title{
Tensile behavior of a Brazilian Disk Containing non-persistent Joint Sets Subjected to Diametral Loading: An Experimental Investigation
}

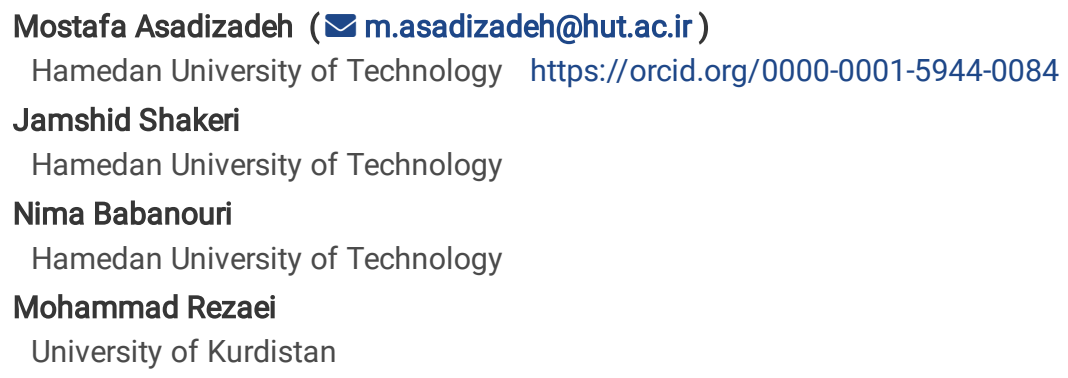

Research Article

Keywords: Non-persistent joint, Brazilian disk, Tensile strength, Cracking behavior

Posted Date: August 18th, 2021

DOI: https://doi.org/10.21203/rs.3.rs-758586/v1

License: (c) This work is licensed under a Creative Commons Attribution 4.0 International License. Read Full License 


\section{Abstract}

Structural defects are part of the inherent characteristics of rock masses. They can be found in the form of fishers, joints, and beddings and can be divided into persistent or non-persistent one. The coalescence of non-persistent cracks may lead to the formation of persistent joints under the tensile stress field, leading to instability of rock mass. The mechanical behavior of non-persistent jointed disks under tensile stress has essential implications for rock engineering structures. In this paper, concrete Brazilian disks containing open non-persistent joints were constructed and subjected to diametral loading to investigate the effect of this kind of joint parameters on the tensile strength and stiffness of disks. The effect of some parameters, such as joint continuity factor (the relationship between joint length and rock bridge length), bridge angle, joint spacing, and loading direction with respect to joint angle were investigated to estimate the tensile strength and stiffness as well as failure pattern. The results of experiments revealed that the tensile strength, stiffness, and failure pattern of Brazilian disks are highly affected by nonpersistent pre-existing crack parameters. The increase of joint continuity factor and loading direction leads to an increase in tensile strength and a decrease in stiffness. However, when bridge angle and spacing increase tensile strength rises, and the former decreases stiffness while the latter results in its reduction. Finally, all the parameters significantly affect the failure pattern, and some failure patterns such as step-path failure, splitting, or sliding may occur as a function of non-persistent joint parameters.

\section{Introduction}

A rock mass is a natural geological material that is formed of two components, intact rock and discontinuity (Asadizadeh et al. 2018b; Chen et al. 2020). The term discontinuity generally includes fractures, fissures, joints, faults, and bedding planes (Mas Ivars et al. 2011). Many rock structures, such as civil, hydropower, and mining projects are often constructed on or in a jointed rock mass. Therefore, the presence of nonpersistent joints may reduce the strength of rock mass and trigger new cracks, leading to the failure of rock structures (Morgan et al. 2013; Zhou et al. 2014; Shang et al. 2018b). In many rock engineering failures (for example, landslide of the rock mass slope, and collapse failure of underground rock engineering), it is believed that the opening and slipping of pre-existing joints are the main causes of geological disasters (Shang et al. 2018b; Shou et al. 2019). The stability of jointed rock structures is significantly affected by crack initiation and propagation under tensile stress filed due to the unloading effect of rock excavation or construction of openings in rock masses (Yang et al. 2020). Many researchers have conducted experimental studies on real rock or rock-like specimens with pre-fabricated discontinuities, and some significant results have been reported (Goldstein ao et al. 1966; Hayashi 1966; Einstein et al. 1969; Brown and Trollope 1970; Einstein and Hirschfeld 1973; Singh et al. 2002; Asadizadeh et al. 2018a, 2019a; Asadizadeh and Rezaei 2019; Shaunik and Singh 2019) and numerically (Singh and Singh 2008; Wang et al. 2016, 2017; Ma et al. 2018; Chang et al. 2019), and fewer researchers have studied the nonpersistent joints (Lajtai 1969; Bobet and Einstein 1998; Bobet 2000; Gehle and Kutter 2003; Wong and Einstein 2009; Park and Bobet 2009, 2010; Ghazvinian et al. 2012; Zhang and Wong 2013; Asadizadeh et al. 2019a, b; Fereshtenejad and Song 2021). However, the tensile strength of nonpersistent jointed rock mass has not been studied in-depth (Chen et al. 2012; Cheng et al. 2016; Shang et al. 2018a; Xiong and Chen 2020; Lin et al. 2020; Yang et al. 2020) and much research is required to explore the tensile behavior of rock bridges and their surrounding rock mass.

Investigation into tensile strength, stiffness, and failure pattern of non-persistent jointed disks under diametral loading may benefit rock engineers by providing them with an in-depth insight into the failure mechanism of rock structures under static loads in cases such as underground spaces, tunnels, and slopes, and may help them to prevent instability at the design stage, resulting in a safe design of these structures, leading to the reduction of failure hazards. In this paper, 51 Brazilian concrete disks, containing various configurations of nonpersistent joints have been subjected to diametral loading to investigate the effect of joint continuity $k$, joint spacing $d$, bridge angle $\gamma$, and loading direction $\beta$ on their tensile strength and stiffness through physical experiments (see Fig. 1).

\section{Experimental Study}

Concrete Brazilian disk specimens with a diameter of $150 \mathrm{~mm}$ and a height of $75 \mathrm{~mm}$ were constructed using a mixture of cement, sand, and water by a weight ratio of 3.5: 5:3. The samples were cured at room temperature for 14 days. Five uniaxial compression and Brazilian tests were performed on cylindrical and disk specimens respectively to obtain their mechanical properties. The mechanical properties of the final product are shown in Table 1. A geologic material proxy with the reported mechanical properties can be classified as a weak to medium rock sample according to the Brady and Brown classification system (Brady and Brown 2004).

A specific mold was designed and manufactured using Plexiglass and PVC tube. A grid of slots was created at the base of the model which acts as a host for the vertical blades. These blades are embedded in concert to create non-persistent joints. For this purpose, a pre-designed pattern was installed at the bottom of the model, and blades were fixed in the grid. All component of the mold and base grid is presented in Fig. 2.

After casting, the mold was shaken to condense the mortar and release any trapped air from the mixture. After four hours, the blades were removed from the mold, and non-persistent joints were created, see Fig. 3. 
In this study, 51 diametral loading tests were performed on non-persistent jointed Brazilian disks using a uniaxial loading machine. Actual control of loading speed during the compressive strength test is one of the determining parameters in the test result, which in this study was $0.005 \mathrm{~mm} / \mathrm{s}$. In this experiment, the LVDT displacement sensor was used to investigate and calculate the values of stress and strain, as well as to draw a strain stress diagram, which is shown in Fig. 4.

Each test was repeated on the same samples three times and the average value of tensile strength and stiffness are presented in Table 2.

The statistical description of the non-persistent joint parameters and test results are presented in Table 3 , and the histogram of test output is presented in Fig. 5

\section{Mechanical Response Of The Specimens}

In this section tensile strength and stiffness of specimens under diametrical loading have been explored in-depth.

\section{3-1 The effect of joint continuity factor}

\section{3-1-1 Tensile strength}

The effect of the joint continuity factor on indirect tensile strength was investigated using experimental experiments. In these tests, the joint continuity factor varied by $0.18,0.22,0.29,0.40$, and 0.67 while other parameters were at their average. The test was repeated three times for each specimen the results are presented in Fig. 6 . As it can be seen in this figure, by increasing $k$ from 0.18 to 0.22 tensile strength increases by $24.7 \%$ and then there is a $34.25 \%$ reduction at central point, i.e. $k=0.29$, finally as $k$ increases to 0.67 tensile strength decreases by $41.5 \%$. Overally by increasing $k$, tensile strength decreases.

\section{3-1-2 Tensile stiffness}

The impact of the joint continuity factor on tensile stiffness is presented in Fig. 8. This parameter was calculated from the axial-forcedisplacement curve during the test of Brazilian disks (see Fig.7).

By increasing $k$ from 0.18 to 0.67 tensile stiffness generally decreases by $95.43 \%$; however, there is some fluctuation at $k=0.22$ and 0.4 . The variation pattern of tensile strength and stiffnes are the sanme as each other.

\section{3-1-3 The failure pattern}

The effect of the joint continuity factor on the failure mechanism of samples is presented in Fig. 9. The failure pattern is significantly affected by $k$. When $k=0.67$ the pre-cracks at the center of the sample coalesce and form a sliding surface, and at the top and bottom of the sample new cracks form between the row of pre-existing cracks (see Fig. 9 a). By decreasing $k$ from 0.4 to 0.18 the failure happens in the center of the disk for example when $k=0.4,0.29$, and 0.18 the tips of pre-existing cracks connect to each other by new cracks and failure surface forms (see Fig. 9 b, $\mathrm{c}$ and e). However, when $k=0.22$ the failure mode changes at the center of the specimen, meaning that the new cracks usually form at both ends of pre-existing cracks and create more failure surface (see Fig. 9 d).

\section{3-2 The effect of loading direction}

\section{3-2-1 Tensile strength}

Moreover, the effect of loading direction with respect to joint angle on indirect tensile strength was investigated in-depth. In these tests, loading direction varied from $0^{\circ}$ to $90^{\circ}$ while other parameters were at their average. The test was repeated three times for each specimen the results are presented in Fig. 10. As it can be seen in this figure, by increasing $\beta$ from $0^{\circ}$ to $45^{\circ}$ tensile strength decreases by $22.41 \%$, and then increases as $\beta$ increases to $70^{\circ}$ and finally by increasing $\beta$ from $70^{\circ}$ to $90^{\circ}$ tensile strength decreases by $38.90 \%$. However, the general trend of tensile strength is decreasing as $\beta$ increases.

\section{3-2-2 Tensile stiffness}

The impact of loading direction with respect to joint angle on sample stiffness is presented in (Fig. 12). The linear part of the load-displacement curve during the test represents this parameter (see Fig.11).

In this case, by increasing $\beta$ from $0^{\circ}$ to $90^{\circ}$ tensile stiffness generally decreases by $94.18 \%$. However, at $\beta=20^{\circ}$ and $70^{\circ}$ tensile stiffness increases by $10.98 \%$ and $62.92 \%$ respectively. The maximum and minimum amount of stiffness is reported for $\beta=70^{\circ}$ and $\beta=90^{\circ}$ respectively. It seems that at $\beta=20^{\circ}$ just one pre-existed crack contributes to failure surface, and at $\beta=70^{\circ}$ three cracks participate in the failure process. 
The effect of loading direction with respect to joint angle on the failure mechanism of samples is presented in Fig. 13. The loading direction can virtually affect the failure. When $\beta=0^{\circ}$ the pre-cracks at the center of the sample coalesce and form a failure surface (see Fig. 13 a). At $\beta=20^{\circ}$ just one pre-existing crack contributes to the failure surface, and it developed in the intact part of the specimen (see Fig $13 \mathrm{~b}$ ). However, at $\beta=45^{\circ}$ the right tip of the central cracks contributes to the failure surface, and three new cracks formed at the upper side of the sample due to the compression zone right below the loading platen (see Fig. $13 \mathrm{c}$ ). When $\beta=70^{\circ}$, almost all central cracks participate in failure surface, and cracks usually initiate from both sides of pre-existed cracks (see Fig. $13 \mathrm{~d}$ ). At $\beta=90^{\circ}$, the failure surface moves from the center to the left side of the sample, and in this case, just one side of the cracks participates in the failure surface (see Fig. 13 e).

\section{3-3 The effect of bridge angle}

\section{3-3-1 Tensile strength}

The effect of bridge angle on tensile strength was investigated using Brazilian disks. In these tests, bridge angle varied from $90^{\circ}$ to $150^{\circ}$ while other parameters were at their average, and the results are presented in Fig. 14 . As it can be seen in this figure, at first by increasing $\gamma$ from $90^{\circ}$ to $112.5^{\circ}$ tensile strength increases by $14.91 \%$, then by increasing $\nu$ from $112.5^{\circ}$ to $121.5^{\circ}$ tensile strength decreases by $27.03 \%$, and then by increasing $\gamma$ from $121.5^{\circ}$ to $130.5^{\circ}$ tensile strength increases by $41.23 \%$, finally by increasing $\gamma$ from $130.5^{\circ}$ to $150^{\circ}$ tensile strength decreases by $11.54 \%$. Generally, by increasing $\gamma$ from $90^{\circ}$ to $150^{\circ}$ tensile strength increases by $4.76 \%$.

\section{3-3-2 Tensile stiffness}

The impact of bridge angle on sample stiffness is presented in (Fig. 16). The stiffness is calculated from the linear part of the loaddisplacement curve during the test (see Fig.15).

Moreover, Fig. 15 shows the effect of bridge angle on sample stiffness. As it can be seen in this figure, by increasing $\nu$ from $90^{\circ}$ to $150^{\circ}$ tensile stiffness generally decreases by $57.96 \%$. However, there is $91.11 \%$ increase at $\gamma=130.5^{\circ}$ and then stiffness decreases.

\section{3-3-3 The effect of bridge angle on failure pattern}

The effect of bridge angle on the failure mechanism of samples is presented in Fig. 17. This parameter can virtually affect the failure pattern. When $\mathrm{y}=90^{\circ}, 121.5^{\circ}, 130.5^{\circ}$, and $150^{\circ}$ the failure surface develops through both pre-cracks and intact concrete (see Fig. 13 a, b, c and e), and more than one crack develops in the compression zone right below the upper loading platen. At $\mathrm{y}=112.5^{\circ}$ both ends of pre-cracks contribute to filature surface, especially from center to the lower part of the sample (see Fig $17 \mathrm{~b}$ ).

\section{3-4 The effect of joint spacing}

\section{3-4-1 Tensile strength}

The impact of joint spacing on tensile strength is shown in Fig.18. As it can be seen in this figure, by increasing $d$ from 1.4 to $4.2 \mathrm{~cm}$ tensile strength generally increases by $17.58 \%$; however, there is a local drop in tensile strength at $d=2.8 \mathrm{~cm}$.

\section{3-4-2 Tensile stiffness}

The impact of joint spacing on sample stiffness was investigated using force-displacement curves (see Fig. 20). The slope of the linear part of the curve represents the tensile stiffness.

The calculated stiffness is presented in Fig.20. As it can be seen in this figure, by increasing $d$ from 1.4 to $4.2 \mathrm{~cm}$ generally stiffness increases by $33.88 \%$; however, stiffness decreases at $d=2.8 \mathrm{~cm}$ and $4.2 \mathrm{~cm}$ by $35.52 \%$ and $20.68 \%$ respectively.

\section{3-4-3 The effect of joint spacing on failure pattern}

The effect of joint spacing on the failure pattern is presented in Fig. 21. Spacing was increased at levels 1.4, 2.1, 2.8, 3.5, and 4.2 cm to investigate its effect on the failure mechanism of Brazilian disks. When $d=1.4$ and $2.8 \mathrm{~cm}$, step-path failure happens due to the function of nonpersistent pre-existing cracks (see Fig. 21 a and d). This mechanism can be seen soundly at $\mathrm{d}=1.4 \mathrm{~cm}$ but when $\mathrm{d}=3.5 \mathrm{~cm}$ the steps are much steeper and the failure surface paths from the center of the sample. At $\mathrm{d}=21 \mathrm{~cm}$ and $2.8 \mathrm{~cm}$, the failure surface paths through intact concrete and pre-existing joints too, and is located at the center of the sample. It means that the failure is more affected by tensile stress at the center of the sample than the function of pre-cracks (see Fig. $21 \mathrm{~b}$ and c). The failure mechanism of $d=4.2 \mathrm{~cm}$ is virtually the same. The failure surface is not perpendicular and due to the functionality of the compression zone right below the loading platens more cracks imitate (see Fig. 21e)

\section{Conclusion}


In this paper, a number of Brazilian concrete disk specimens containing a set of open non-persistent joints were subjected to diametral loading to investigate the effect of joint continuity factor $k$, joint spacing $d$, bridge angel $\gamma$, and loading direction with respect to joint angle $\beta$ on the tensile strength, stiffness and failure pattern. The results indicate that tensile strength, stiffness, and failure pattern of Brazilian disks are significantly affected by the function of non-persistent pre-existing crack parameters. As the $k$ and $\beta$ increase, tensile strength decreases, and by increasing $\gamma$ and $d$ this parameter increase. Moreover, by increasing $k, \beta$ and $\gamma$ stiffness decreases but when $d$ rises stiffness increases. Nonpersistent crack parameters may also affect the failure pattern of samples. When $k$ increases from 0.18 to 0.67 , the failure pattern changes from splitting at the center to the sliding mode. Moreover, by increasing $\beta$ from $0^{\circ}$ to $90^{\circ}$ the failure surface moves from center to the sides of the sample. At higher and lower levels of $\gamma$ i.e., $90^{\circ}$ and $150^{\circ}$, the splitting mode is dominant at the center of the sample, but at the middle levels of $y$ i.e., $112.5^{\circ}, 121.5^{\circ}$, and $130^{\circ}$, both ends of existing cracks contribute to failure surface and forms a more complicated failure surface. Finally, joint spacing $d$ can affect the failure pattern more severely. At the low level of $d$ (i.e., $1.4 \mathrm{~cm}$ ), step-path failure is dominated and by increasing $d$ to the middle level, the failure pattern is more complicated, and at higher levels of $d$ (i.e., $4.2 \mathrm{~cm}$ ), mainly intact part of specimen contributes to the failure surface. Future work for this research involves extensive numerical investigations and an upgrade to an experimental setup to record the cracking process using advanced technics such as digital image correlation and acoustic emission technics.

The authors declare that they have no known competing financial interests or personal relationships that could have appeared to influence the work reported in this paper.

\section{References}

Asadizadeh M, Hossaini MF, Moosavi M, et al (2019a) Mechanical characterisation of jointed rock-like material with non-persistent rough joints subjected to uniaxial compression. Eng Geol 260:105224. https://doi.org/10.1016/j.enggeo.2019.105224

Asadizadeh M, Masoumi H, Roshan H, Hedayat A (2019b) Coupling Taguchi and Response Surface Methodologies for the Efficient Characterization of Jointed Rocks' Mechanical Properties. Rock Mech Rock Eng 52:4807-4819. https://doi.org/10.1007/s00603-019-01853-1

Asadizadeh M, Moosavi M, Hossaini MF (2018a) Investigation of mechanical behaviour of non-persistent jointed blocks under uniaxial compression. Geomech Eng 14:29-42. https://doi.org/10.12989/gae.2018.14.1.029

Asadizadeh M, Moosavi M, Hossaini MF, Masoumi H (2018b) Shear Strength and Cracking Process of Non-persistent Jointed Rocks: An Extensive Experimental Investigation. Rock Mech Rock Eng 51:415-428. https://doi.org/10.1007/s00603-017-1328-6

Asadizadeh M, Rezaei M (2019) Surveying the mechanical response of non-persistent jointed slabs subjected to compressive axial loading utilising GEP approach. Int J Geotech Eng. https://doi.org/10.1080/19386362.2019.1596610

Bobet A (2000) The initiation of secondary cracks in compression. Eng Fract Mech 66:187-219. https://doi.org/10.1016/S00137944(00)00009-6

Bobet A, Einstein HH (1998) Fracture coalescence in rock-type materials under uniaxial and biaxial compression. Int J Rock Mech Min Sci 35:863-888. https://doi.org/10.1016/S0148-9062(98)00005-9

Brady BHG, Brown ET (2004) Rock Mechanics for underground mining. Springer Netherlands, Dordrecht

Brown ET, Trollope DH (1970) Strength of a model of jointed rock. J Soil Mech Found Div 96:685-704

Chang L, Konietzky H, Frühwirt T (2019) Strength Anisotropy of Rock with Crossing Joints: Results of Physical and Numerical Modeling with Gypsum Models. Rock Mech Rock Eng 52:2293-2317. https://doi.org/10.1007/s00603-018-1714-8

Chen M, Yang S-Q, Ranjith PG, Zhang Y-C (2020) Cracking behavior of rock containing non-persistent joints with various joints inclinations. Theor Appl Fract Mech 109:102701. https://doi.org/10.1016/j.tafmec.2020.102701

Chen X, Liao Z, Peng X (2012) Deformability characteristics of jointed rock masses under uniaxial compression. Int J Min Sci Technol 22:213221. https://doi.org/10.1016/j.ijmst.2011.08.012

Cheng C, Chen X, Zhang S (2016) Multi-peak deformation behavior of jointed rock mass under uniaxial compression: Insight from particle flow modeling. Eng Geol 213:25-45. https://doi.org/10.1016/j.enggeo.2016.08.010

Einstein HH, Hirschfeld RC (1973) Model studies on mechanics of jointed rock. J Soil Mech Found Div 99:229-248

Einstein HH, Hirschfeld RC, Nelson RA, Bruhn RW (1969) Model studies of jointed-rock behavior. In: The 11th US symposium on rock mechanics (USRMS). American Rock Mechanics Association 
Fereshtenejad S, Song JJ (2021) Applicability of powder-based 3D printing technology in shear behavior analysis of rock mass containing nonpersistent joints. J Struct Geol 143:104251. https://doi.org/10.1016/j.jsg.2020.104251

Gehle C, Kutter HK (2003) Breakage and shear behavior of intermittent rock joints. Int J Rock Mech Min Sci 40:687-700

Ghazvinian A, Sarfarazi V, Schubert W, Blumel M (2012) A study of the failure mechanism of planar non-persistent open joints using PFC2D. Rock Mech rock Eng 45:677-693. https://doi.org/10.1007/s00603-012-0233-2

Goldstein ao M, Goosev B, Pvrogovsky N, et al (1966) Investigation of mechanical properties of cracked rock. In: 1st ISRM Congress. International Society for Rock Mechanics and Rock Engineering

Hayashi M (1966) Strength and dilatancy of brittle jointed mass-The extreme value stochastics and anisotropic failure mechanism. In: 1st ISRM Congress. International Society for Rock Mechanics and Rock Engineering

Lajtai EZZ (1969) Shear strength of weakness planes in rock. Int J Rock Mech Min Sci 6:499-515. https://doi.org/10.1016/01489062(69)90016-3

Lin Q, Cao P, Meng J, et al (2020) Strength and failure characteristics of jointed rock mass with double circular holes under uniaxial compression: Insights from discrete element method modelling. Theor Appl Fract Mech 109:102692.

https://doi.org/10.1016/j.tafmec.2020.102692

Ma C, Yao W, Yao Y, Li J (2018) Simulating Strength Parameters and Size Effect of Stochastic Jointed Rock Mass using DEM Method. KSCE J Civ Eng 22:4872-4881. https://doi.org/10.1007/s12205-017-1581-y

Mas Ivars D, Pierce ME, Darcel C, et al (2011) The synthetic rock mass approach for jointed rock mass modelling. Int J Rock Mech Min Sci 48:219-244. https://doi.org/10.1016/j.ijrmms.2010.11.014

Morgan SP, Johnson CA, Einstein HH (2013) Cracking processes in Barre granite: fracture process zones and crack coalescence. Int J Fract 180:177-204. https://doi.org/10.1007/s10704-013-9810-y

Park CH, Bobet A (2009) Crack coalescence in specimens with open and closed flaws: A comparison. Int J Rock Mech Min Sci 46:819-829. https://doi.org/10.1016/j.ijrmms.2009.02.006

Park CH, Bobet A (2010) Crack initiation, propagation and coalescence from frictional flaws in uniaxial compression. Eng Fract Mech 77:27272748. https://doi.org/10.1016/j.engfracmech.2010.06.027

Shang J, West LJ, Hencher SR, Zhao Z (2018a) Tensile strength of large-scale incipient rock joints: a laboratory investigation. Acta Geotech 13:869-886. https://doi.org/10.1007/s11440-017-0620-7

Shang J, West LJ, Hencher SR, Zhao Z (2018b) Geological discontinuity persistence: Implications and quantification. Eng Geol $241: 41-54$. https://doi.org/10.1016/j.enggeo.2018.05.010

Shaunik D, Singh M (2019) Strength behaviour of a model rock intersected by non-persistent joint. J Rock Mech Geotech Eng 11:1243-1255. https://doi.org/10.1016/j.jrmge.2019.01.004

Shou Y, Zhou X, Berto F (2019) 3D numerical simulation of initiation, propagation and coalescence of cracks using the extended non-ordinary state-based peridynamics. Theor Appl Fract Mech 101:254-268. https://doi.org/10.1016/j.tafmec.2019.03.006

Singh M, Rao KS, Ramamurthy T (2002) Strength and Deformational Behaviour of a Jointed Rock Mass. Rock Mech Rock Eng 35:45-64. https://doi.org/10.1007/s006030200008

Singh M, Singh B (2008) High lateral strain ratio in jointed rock masses. Eng Geol 98:75-85. https://doi.org/10.1016/j.enggeo.2007.11.004

Wang P, Ren F, Miao S, et al (2017) Evaluation of the anisotropy and directionality of a jointed rock mass under numerical direct shear tests. Eng Geol 225:29-41. https://doi.org/10.1016/j.enggeo.2017.03.004

Wang P, Yang T, Xu T, et al (2016) Numerical analysis on scale effect of elasticity, strength and failure patterns of jointed rock masses. Geosci J 20:539-549. https://doi.org/10.1007/s12303-015-0070-x

Wong LNY, Einstein HH (2009) Crack coalescence in molded gypsum and Carrara marble: part 1. Macroscopic observations and interpretation. Rock Mech Rock Eng 42:475-511

Page 6/26 
Xiong LX, Chen HJ (2020) Effects of High Temperatures and Loading Rates on the Splitting Tensile Strength of Jointed Rock Mass. Geotech Geol Eng 38:1885-1898. https://doi.org/10.1007/s10706-019-01137-z

Yang S-Q, Chen M, Huang Y-H, et al (2020) An experimental study on fracture evolution mechanism of a non-persistent jointed rock mass with various anchorage effects by DSCM, AE and X-ray CT observations. Int J Rock Mech Min Sci 134:104469.

https://doi.org/10.1016/j.ijrmms.2020.104469

Zhang X-P, Wong LNY (2013) Crack initiation, propagation and coalescence in rock-like material containing two flaws: a numerical study based on bonded-particle model approach. Rock Mech rock Eng 46:1001-1021

Zhou XP, Cheng H, Feng YF (2014) An Experimental Study of Crack Coalescence Behaviour in Rock-Like Materials Containing Multiple Flaws Under Uniaxial Compression. Rock Mech Rock Eng 47:1961-1986. https://doi.org/10.1007/s00603-013-0511-7

\section{Tables}

Table 1. Material properties of Brazilian concrete disks (Average)

\begin{tabular}{llll} 
Tensile strength $\left(\sigma_{t}, \mathrm{MPa}\right)$ & $\mathrm{UCS}^{*}(\mathrm{MPa})$ & Young's modulus $(\mathrm{E}, \mathrm{GPa})$ & Poisson's ratio $(\mathrm{v})$ \\
\hline 1.88 & 12.96 & 2.44 & 0.25
\end{tabular}

*UCS: uniaxial compressive strength

Table 2. Experiments and the independent and dependent parameters. 


\begin{tabular}{|c|c|c|c|c|c|c|c|c|c|c|c|c|c|}
\hline $\begin{array}{l}\text { Sample } \\
\text { cod }\end{array}$ & $k$ & $d(\mathrm{~cm})$ & $\nu\left(^{\circ}\right)$ & $\beta\left(^{\circ}\right)$ & $K(\mathrm{MN} / \mathrm{mm})$ & $\sigma_{t}(\mathrm{MPa})$ & $\begin{array}{l}\text { Sample } \\
\text { cod }\end{array}$ & $k$ & $d(\mathrm{~cm})$ & $\gamma\left({ }^{\circ}\right)$ & $\beta\left(^{\circ}\right)$ & $K(\mathrm{MN} / \mathrm{mm})$ & $\sigma_{\mathrm{t}}(\mathrm{MPa})$ \\
\hline B1 & 0.67 & 2.8 & 121.5 & 45 & 1.9378 & 1 & B27 & 0.29 & 2.8 & 121.5 & 90 & 1.635 & 1 \\
\hline B2 & 0.67 & 2.8 & 121.5 & 45 & 6.0184 & 0.56 & B28 & 0.29 & 2.8 & 90 & 45 & 141.02 & 1.61 \\
\hline B3 & 0.67 & 2.8 & 121.5 & 45 & 1.3168 & 1.33 & B29 & 0.29 & 2.8 & 90 & 45 & 125.68 & 1.67 \\
\hline B4 & 0.4 & 2.8 & 121.5 & 45 & 57.541 & 1.72 & B30 & 0.29 & 2.8 & 90 & 45 & 168.17 & 1.55 \\
\hline B5 & 0.4 & 2.8 & 121.5 & 45 & 42.174 & 1.61 & B31 & 0.29 & 2.8 & 112.5 & 45 & 61.312 & 1.83 \\
\hline B6 & 0.4 & 2.8 & 121.5 & 45 & 85.837 & 1.61 & B32 & 0.29 & 2.8 & 112.5 & 45 & 84.086 & 1.89 \\
\hline B7 & 0.22 & 2.8 & 121.5 & 45 & 56.781 & 1.83 & B33 & 0.29 & 2.8 & 112.5 & 45 & 61.312 & 1.83 \\
\hline B8 & 0.22 & 2.8 & 121.5 & 45 & 77.079 & 2.05 & B34 & 0.29 & 2.8 & 130.5 & 45 & 71.789 & 2 \\
\hline B9 & 0.22 & 2.8 & 121.5 & 45 & 85.054 & 2.28 & B35 & 0.29 & 2.8 & 130.5 & 45 & 83.802 & 2.05 \\
\hline B10 & 0.18 & 2.8 & 121.5 & 45 & 69.598 & 1.72 & B36 & 0.29 & 2.8 & 130.5 & 45 & 91.771 & 1.67 \\
\hline B11 & 0.18 & 2.8 & 121.5 & 45 & 69.598 & 1.72 & B37 & 0.29 & 2.8 & 150 & 45 & 67.444 & 1.67 \\
\hline B12 & 0.18 & 2.8 & 121.5 & 45 & 63.807 & 1.5 & B38 & 0.29 & 2.8 & 150 & 45 & 50.069 & 1.67 \\
\hline B13 & 0.29 & 2.8 & 121.5 & 0 & 53.613 & 1.72 & B39 & 0.29 & 2.8 & 150 & 45 & 65.303 & 1.72 \\
\hline B14 & 0.29 & 2.8 & 121.5 & 0 & 50.394 & 1.61 & B40 & 0.29 & 1.4 & 121.5 & 45 & 37.097 & 1.5 \\
\hline B15 & 0.29 & 2.8 & 121.5 & 0 & 61.131 & 1.89 & B41 & 0.29 & 1.4 & 121.5 & 45 & 47.859 & 1.72 \\
\hline B16 & 0.29 & 2.8 & 121.5 & 20 & 68.67 & 1.72 & B42 & 0.29 & 1.4 & 121.5 & 45 & 52.243 & 1.5 \\
\hline B17 & 0.29 & 2.8 & 121.5 & 20 & 49.304 & 1.33 & B43 & 0.29 & 2.1 & 121.5 & 45 & 73.575 & 1.67 \\
\hline B18 & 0.29 & 2.8 & 121.5 & 20 & 65.303 & 1.89 & B44 & 0.29 & 2.1 & 121.5 & 45 & 70.071 & 1.5 \\
\hline B19 & 0.29 & 2.8 & 121.5 & 45 & 49.05 & 1.44 & B45 & 0.29 & 2.1 & 121.5 & 45 & 57.113 & 1.61 \\
\hline B20 & 0.29 & 2.8 & 121.5 & 45 & 36.787 & 1.17 & B46 & 0.29 & 3.5 & 121.5 & 45 & 52.147 & 1.89 \\
\hline B21 & 0.29 & 2.8 & 121.5 & 45 & 43.6 & 1.44 & B47 & 0.29 & 3.5 & 121.5 & 45 & 89.71 & 1.5 \\
\hline B22 & 0.29 & 2.8 & 121.5 & 70 & 78.364 & 1.83 & B48 & 0.29 & 3.5 & 121.5 & 45 & 89.71 & 1.17 \\
\hline B23 & 0.29 & 2.8 & 121.5 & 70 & 71.398 & 1.55 & B49 & 0.29 & 4.2 & 121.5 & 45 & 65.303 & 1.83 \\
\hline B24 & 0.29 & 2.8 & 121.5 & 70 & 61.12 & 1.89 & B50 & 0.29 & 4.2 & 121.5 & 45 & 59.187 & 1.83 \\
\hline B25 & 0.29 & 2.8 & 121.5 & 90 & 6.3978 & 1.11 & B51 & 0.29 & 4.2 & 121.5 & 45 & 59.187 & 1.89 \\
\hline B26 & 0.29 & 2.8 & 121.5 & 90 & 1.5823 & 1.11 & & & & & & & \\
\hline
\end{tabular}

Table 3. Statitical description of non-peristent joint parameters and test outputs

\begin{tabular}{lllllllll} 
Type & Parameter & Symbol & Range & Min & Max & Mean & Std. Deviation & Variance \\
\cline { 3 - 8 } Input & Joint continuity factor & $k$ & 0.48 & 0.18 & 0.67 & 0.30 & 0.10 & 0.01 \\
\cline { 2 - 8 } & Joint spacing $(\mathrm{cm})$ & $d$ & 2.80 & 1.40 & 4.20 & 2.80 & 0.54 & 0.29 \\
\cline { 2 - 8 } & Bridge angle (degree) & $\gamma$ & 60.00 & 90.00 & 150.00 & 121.35 & 10.86 & 117.96 \\
\cline { 2 - 9 } & Loading direction (degree) & $\beta$ & 90.00 & 0.00 & 90.00 & 45.00 & 17.83 & 318.00 \\
\hline \multirow{2}{*}{ Output } & Tensile stiffness (MN/mm) & $K$ & 166.85 & 1.32 & 168.17 & 61.57 & 31.97 & 1022.12 \\
\cline { 2 - 8 } & Tensile strength (MPa) & $\sigma_{\mathrm{t}}$ & 1.72 & 0.56 & 2.28 & 1.62 & 0.31 & 0.10
\end{tabular}

\section{Figures}




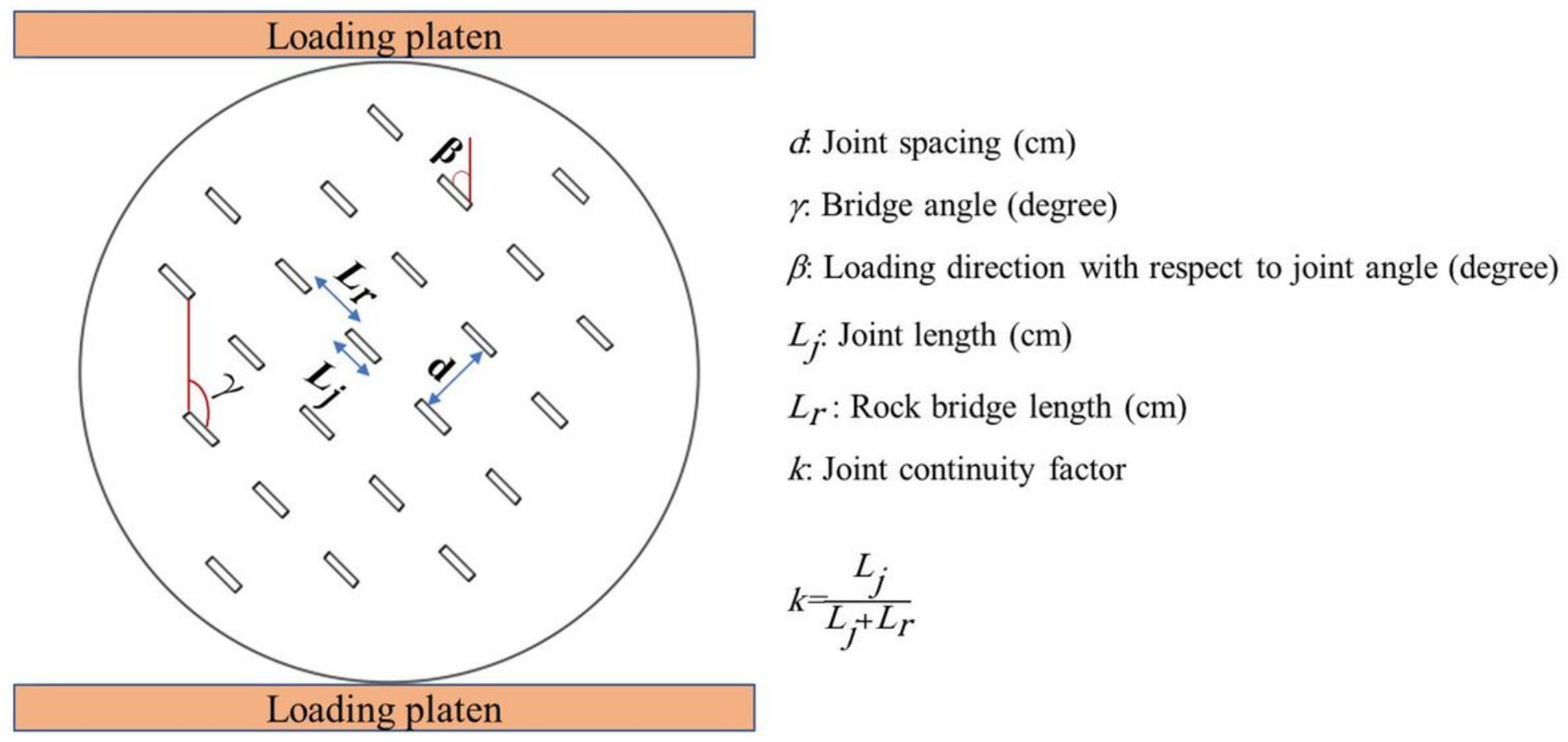

Figure 1

Geometric parameters of the non-persistent jointed disks under diametral loading 


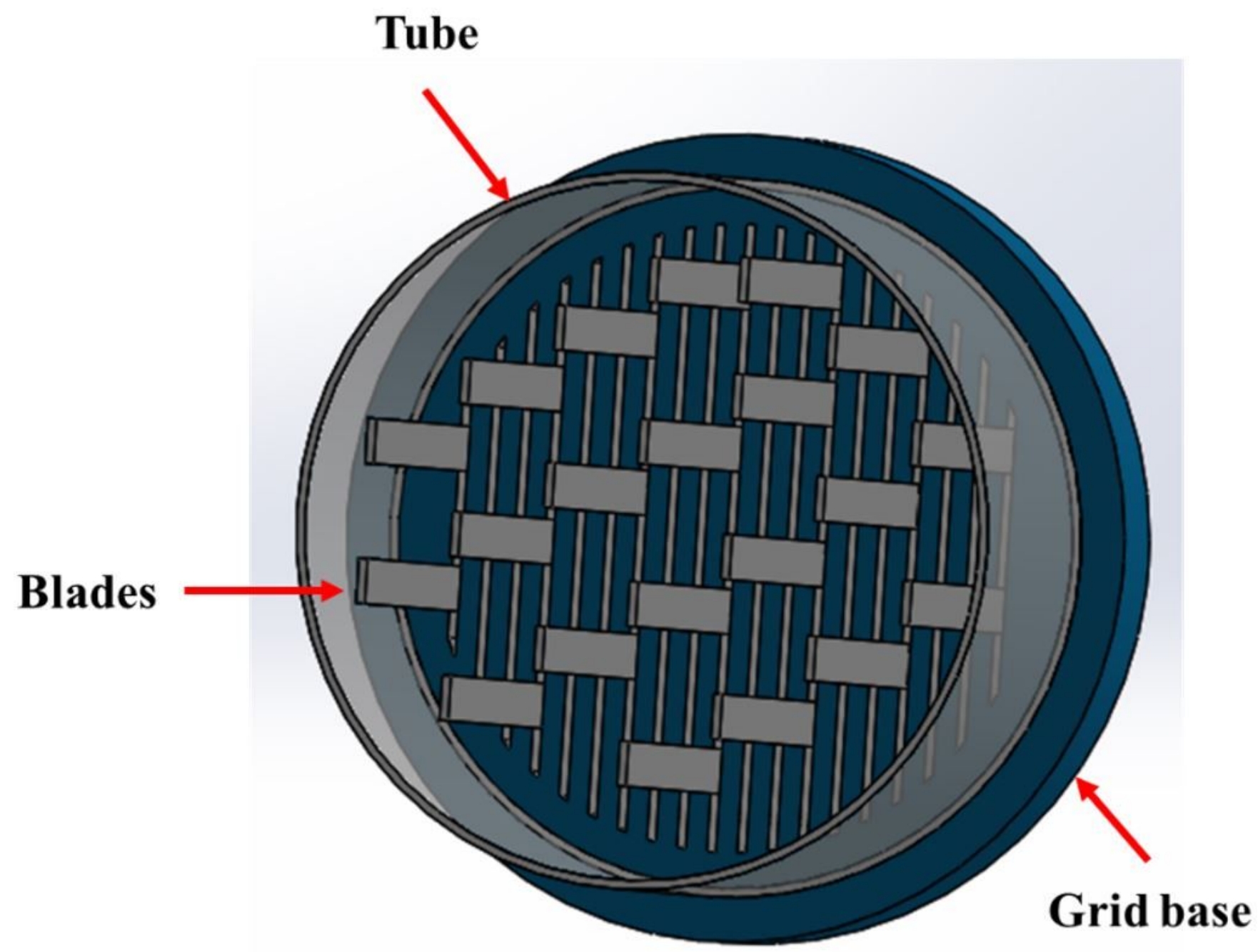

Figure 2

A view of mold made using Plexiglass 


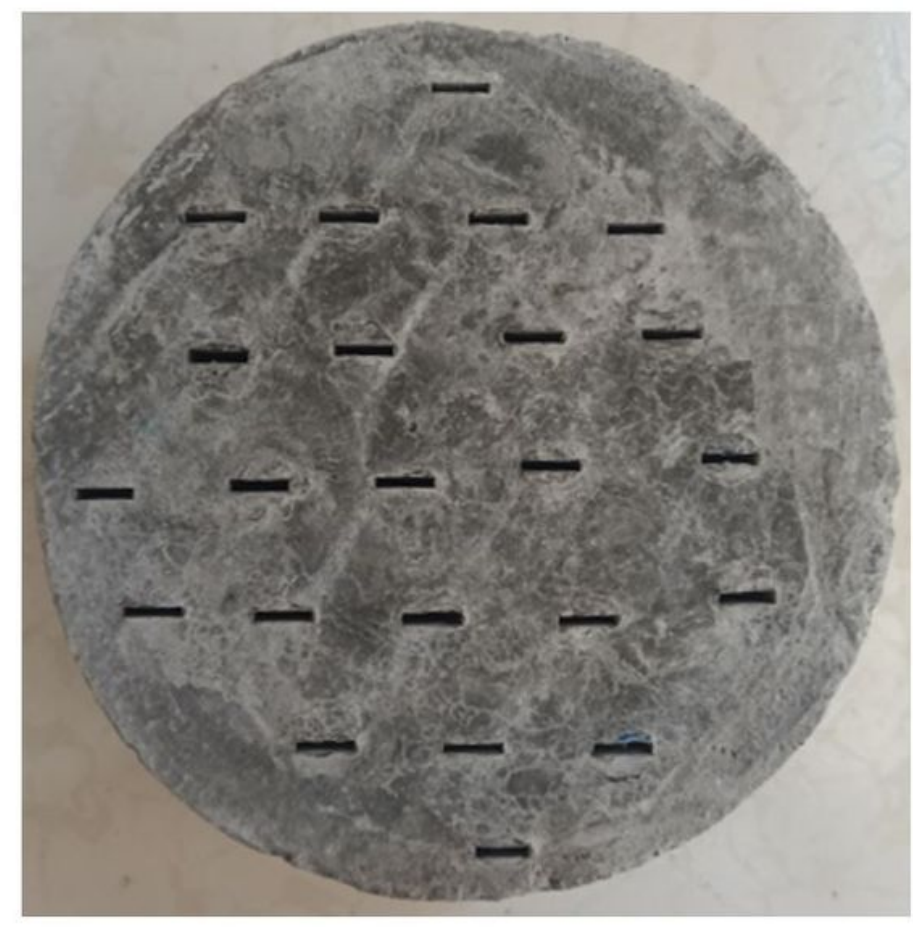

a)

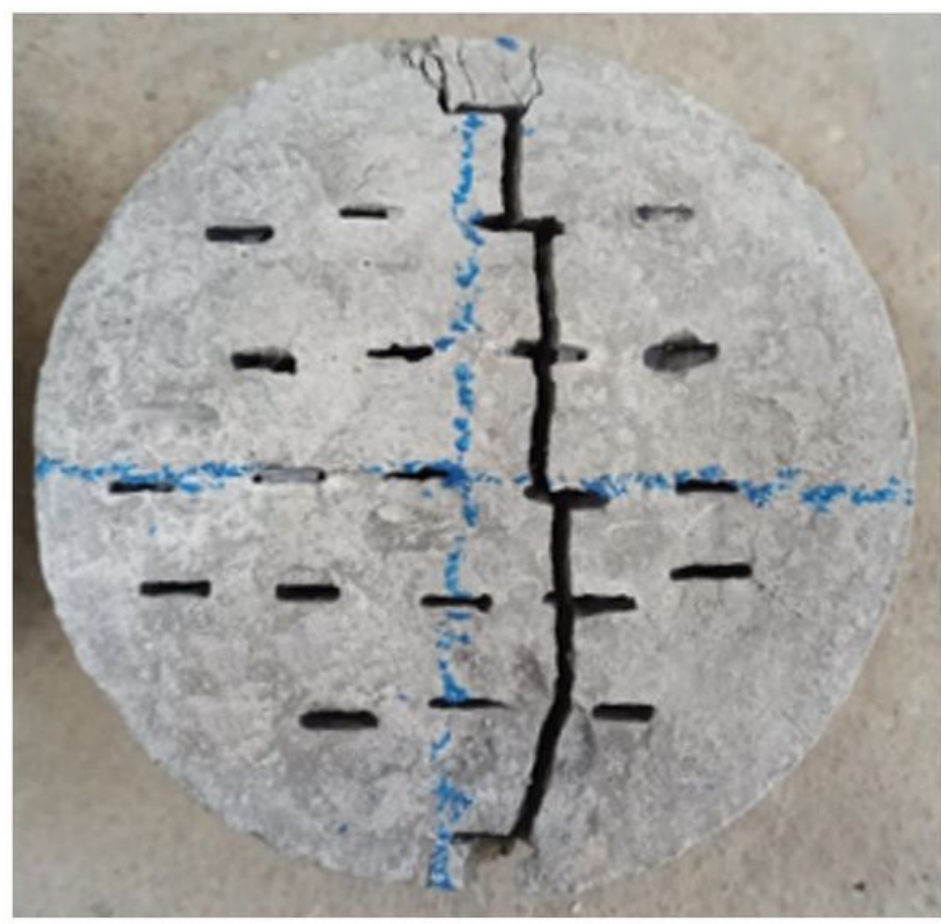

b)

\section{Figure 3}

View of Brazilian concrete disk sample
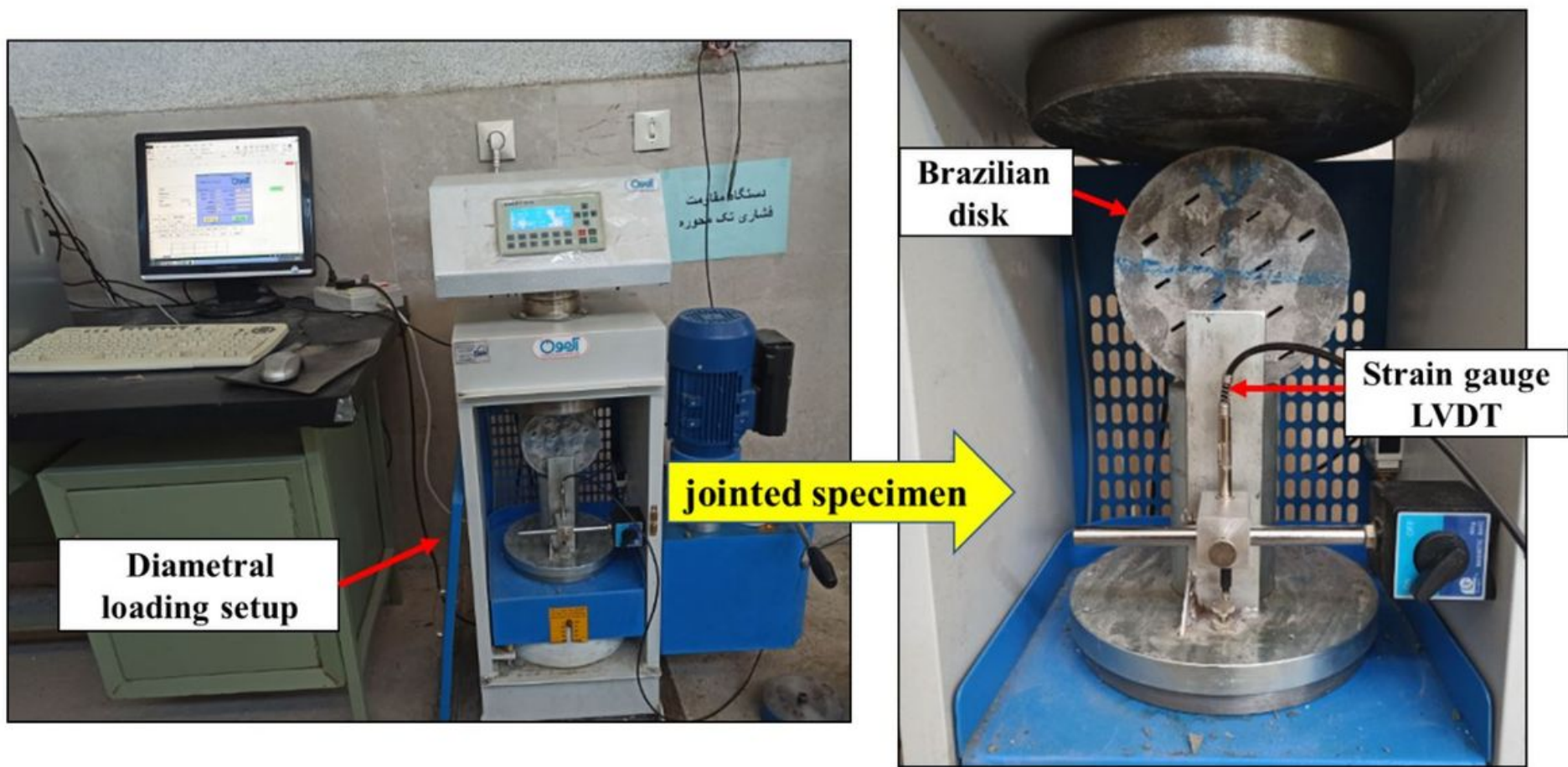

Figure 4

View of the diametral loading setup 


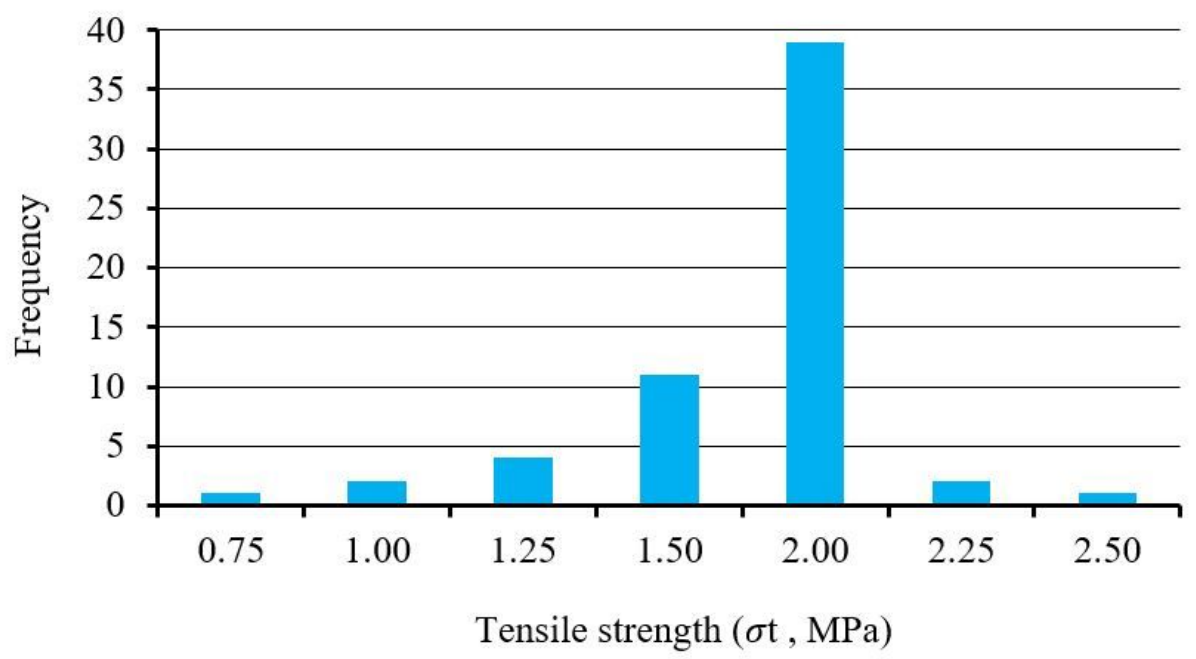

a)

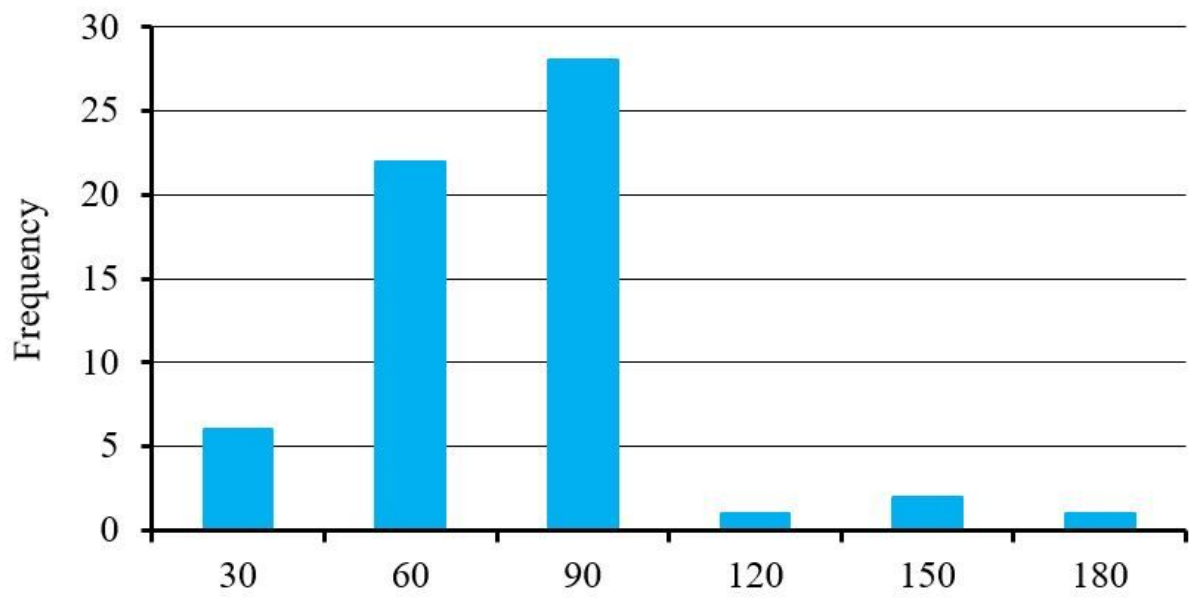

Tensile stiffness ( $\mathrm{K}, \mathrm{MN} / \mathrm{mm})$

b)

Figure 5

The histogram a) Tensile strength (MPa), b) Tensile stiffness (MN/mm) 


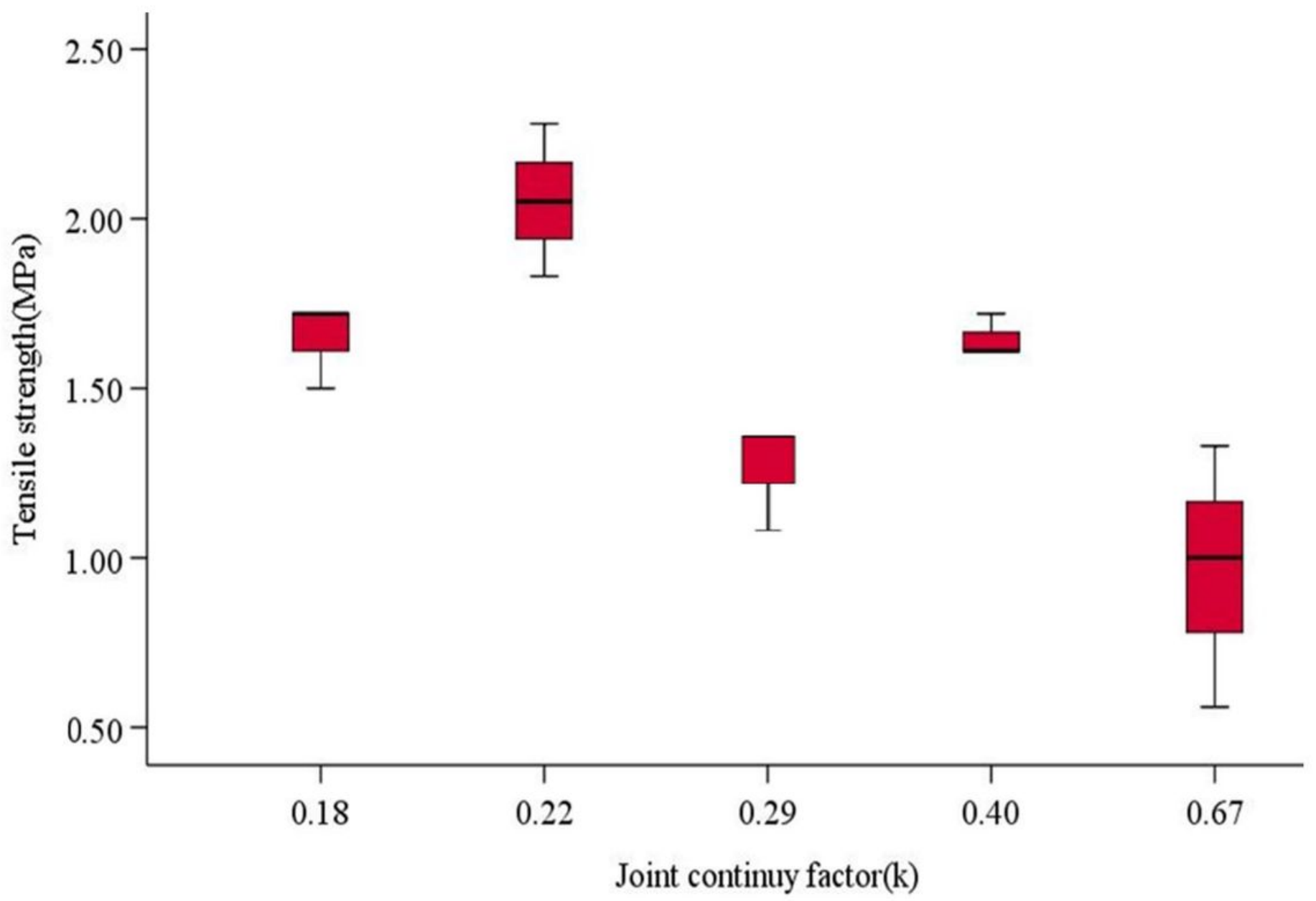

Figure 6

The effect of joint continuity factor on tensile strength 


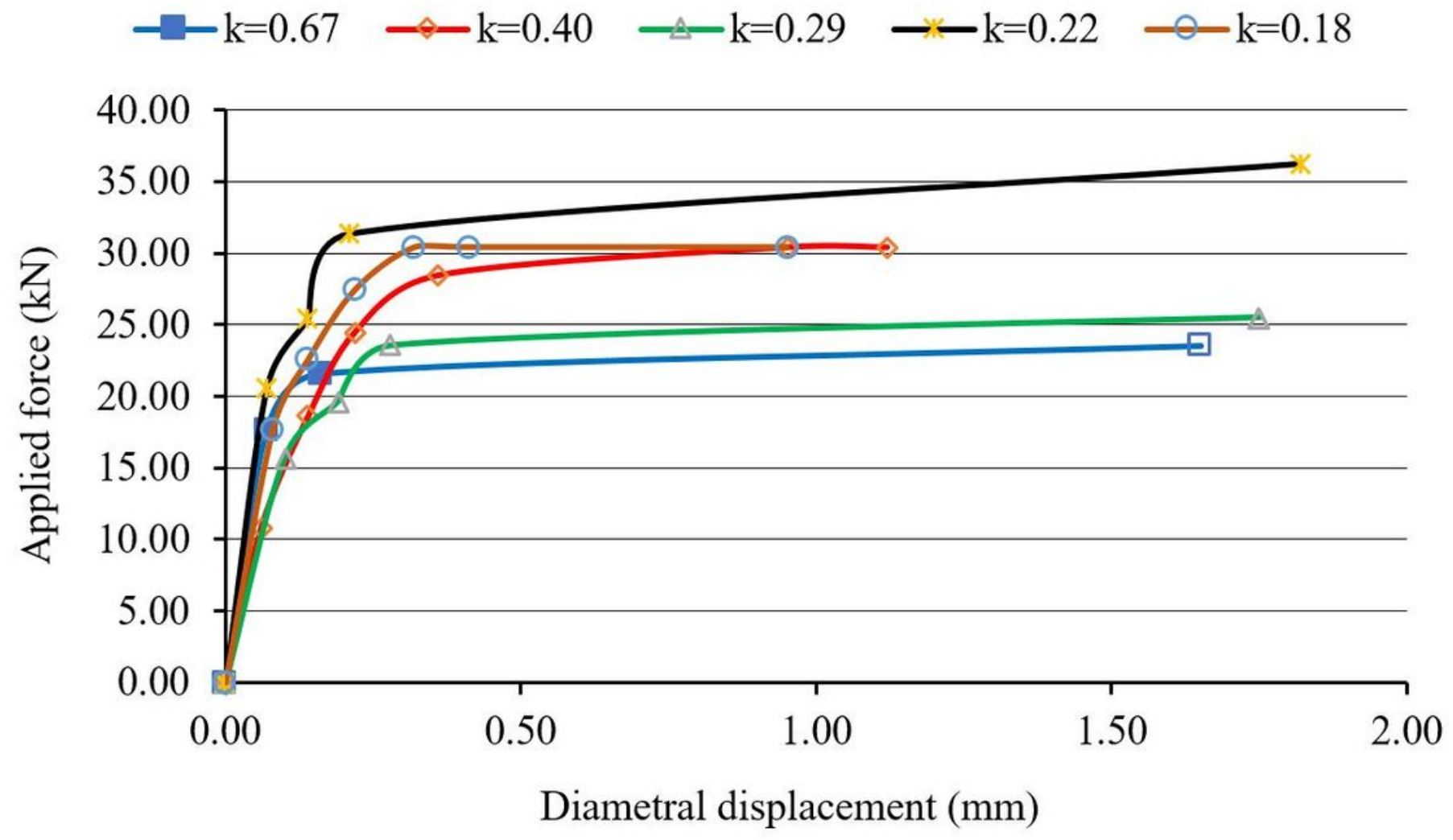

Figure 7

Force-displacement curve of samples with different $k$ 


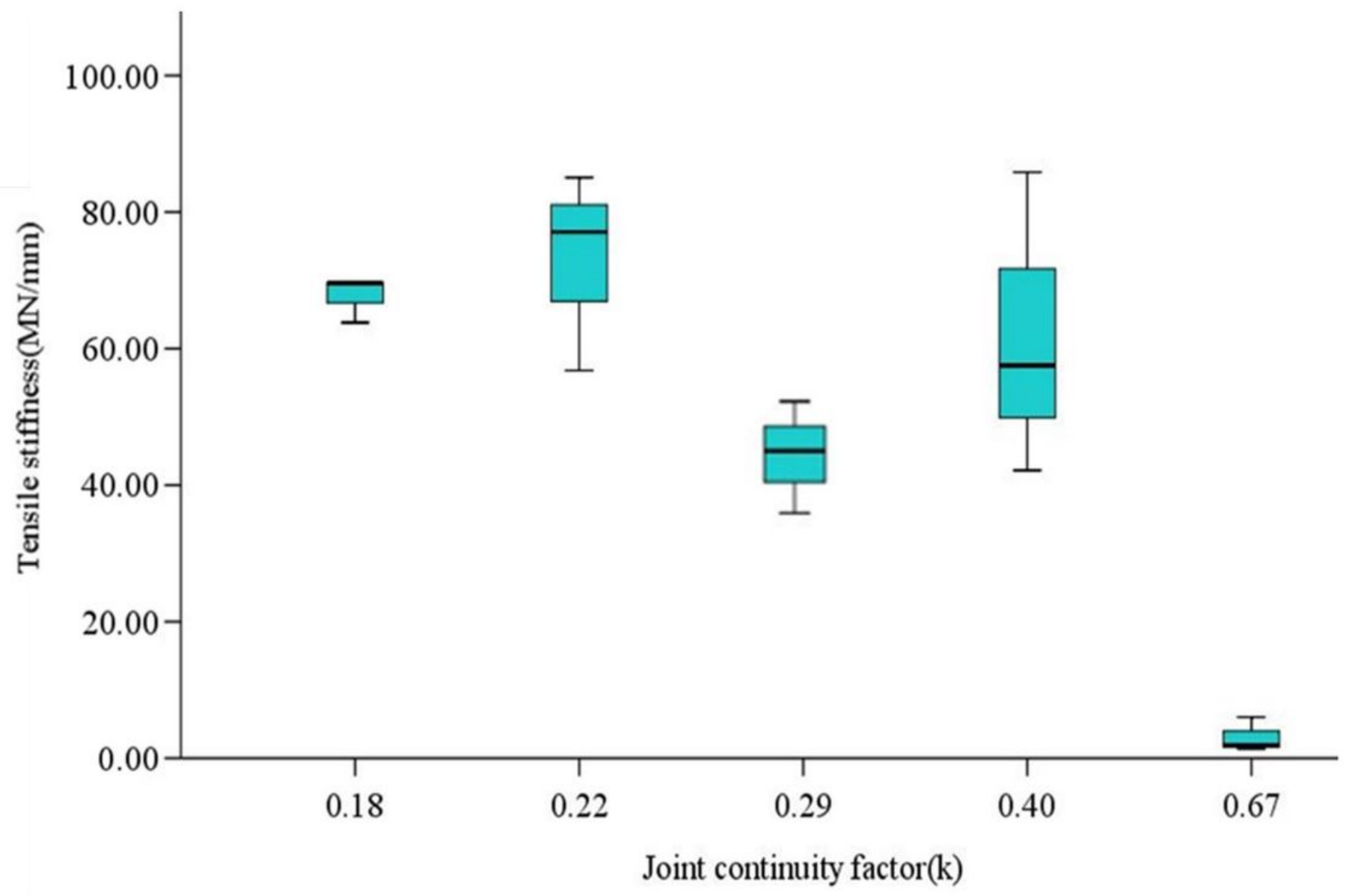

Figure 8

The effect of joint continuity factor on tensile stiffness 

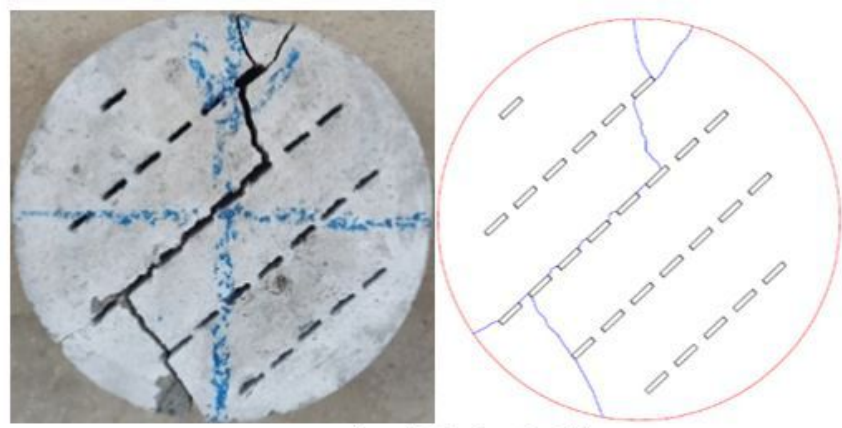

a) $\mathrm{B} 1, \mathrm{k}=0.67$

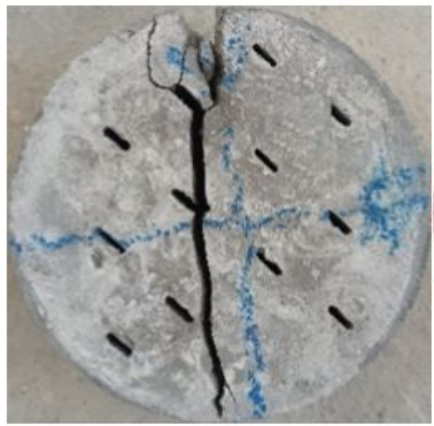

c) $\mathrm{B} 19, \mathrm{k}=0.29$

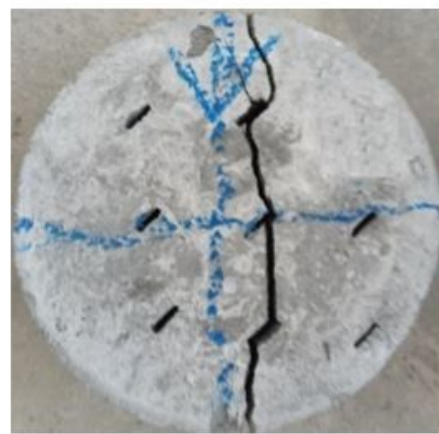

e) $\mathrm{B} 10, \mathrm{k}=0.18$

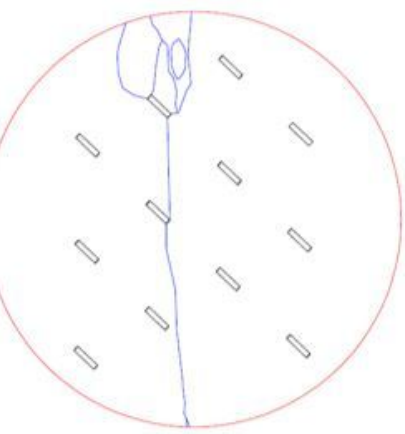

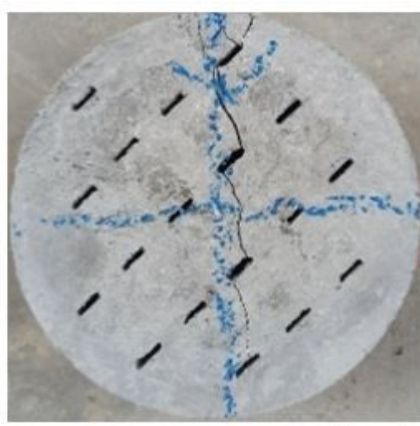

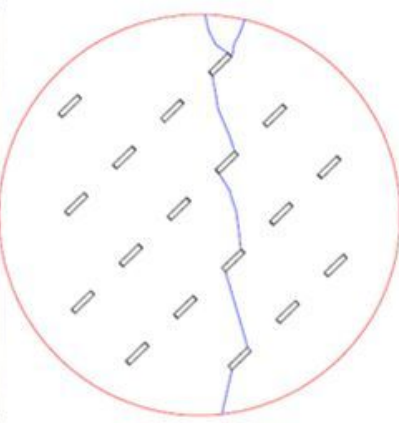

b) $\mathrm{B} 5, \mathrm{k}=0.4$
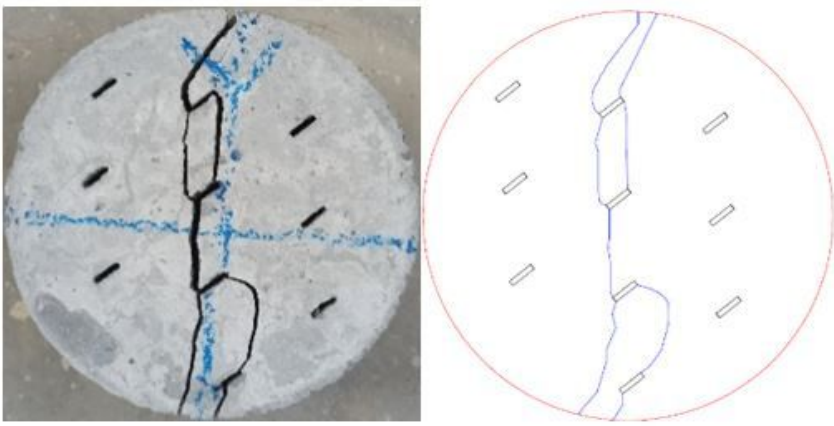

d) $B 8, k=0.22$

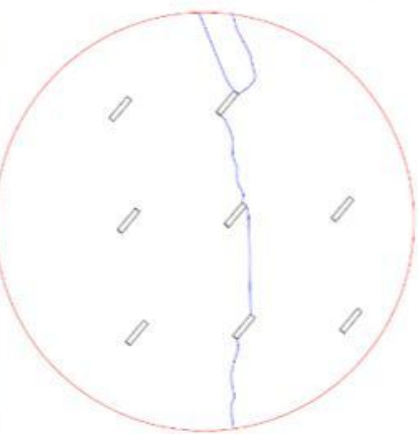

\section{Figure 9}

The effect of joint continuity factor on failure pattern 


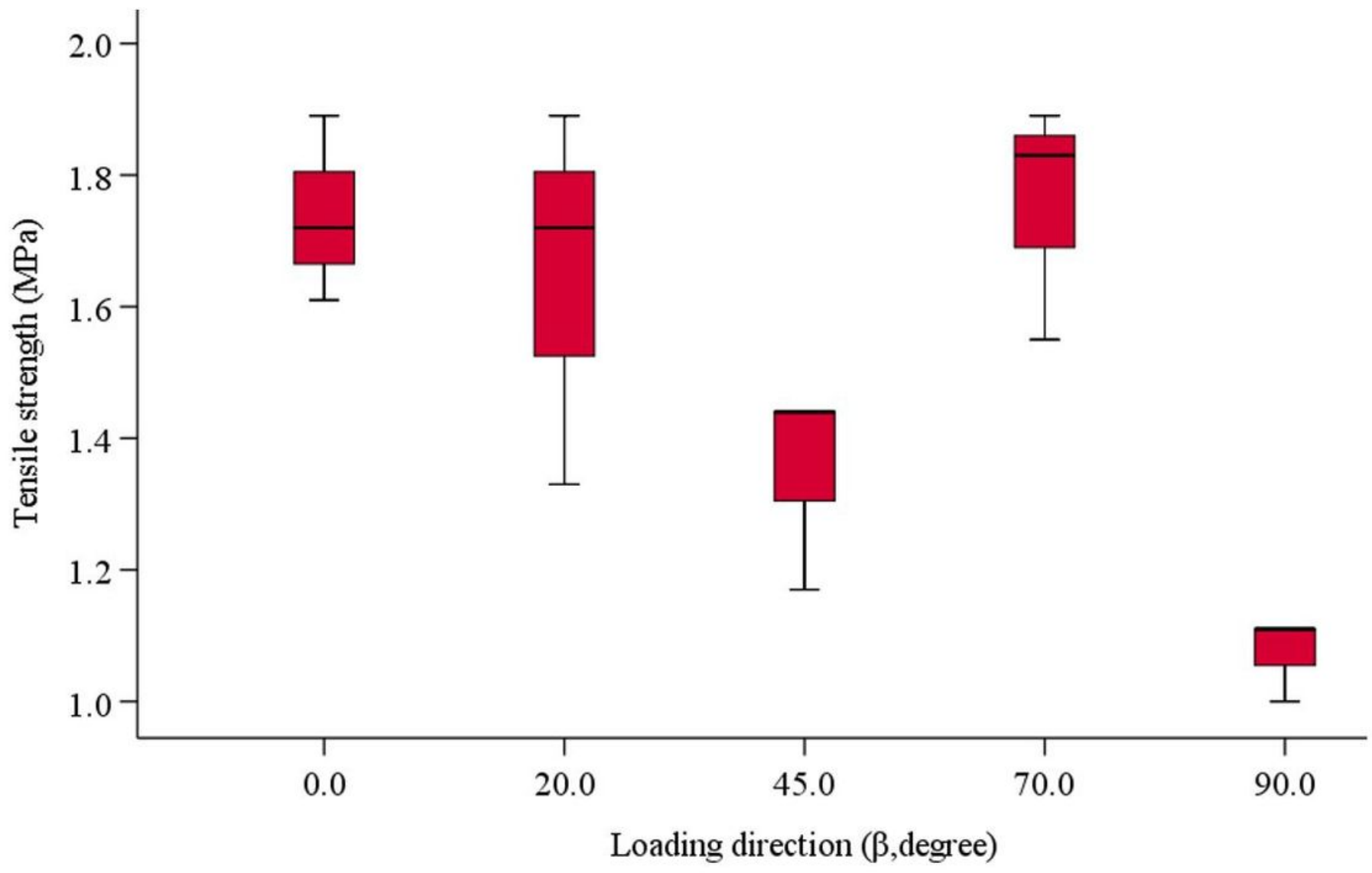

Figure 10

The effect of loading direction on tensile strength
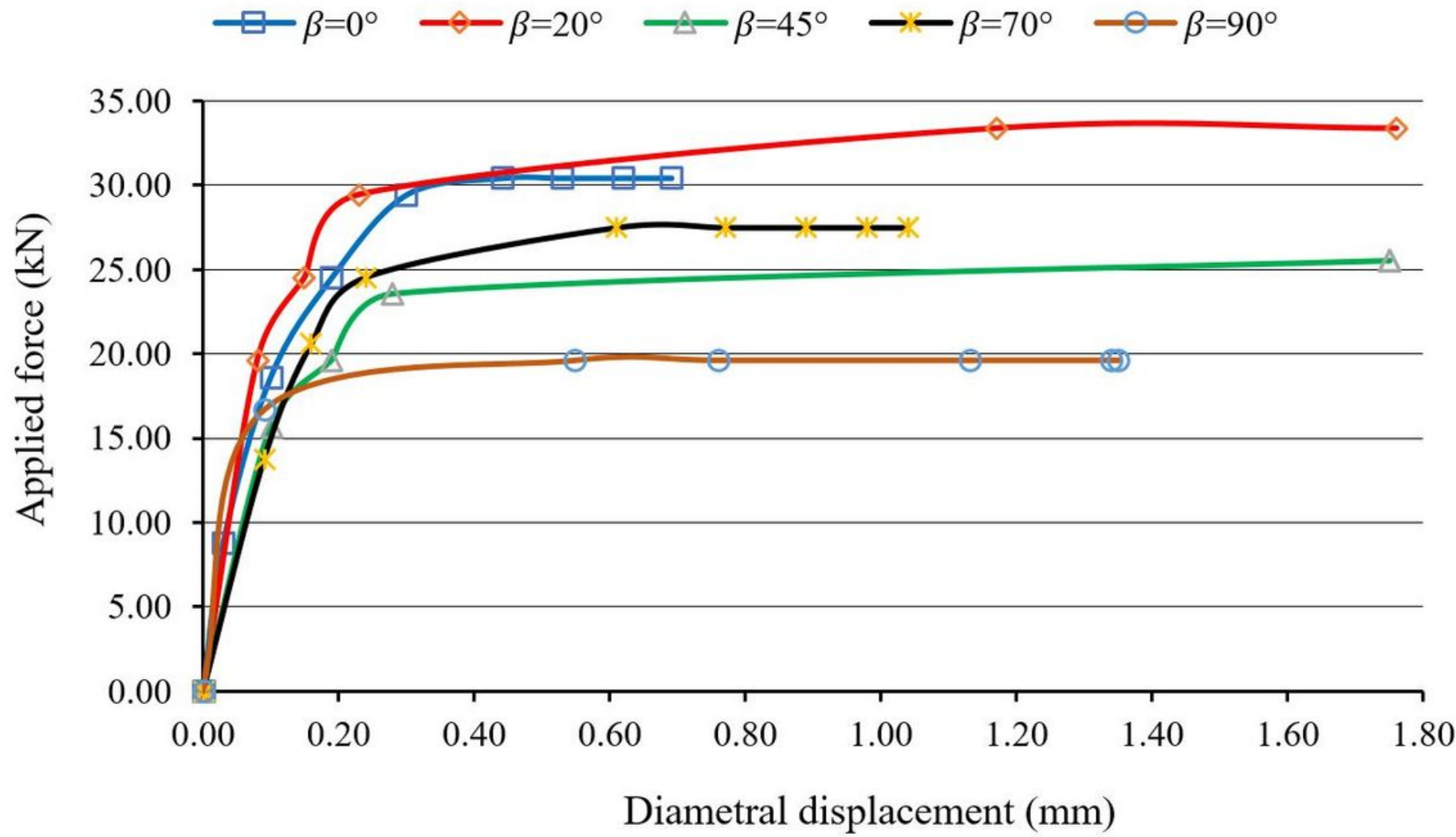

Page $17 / 26$ 
Figure 11

Force-displacement curve of samples with different $\beta$

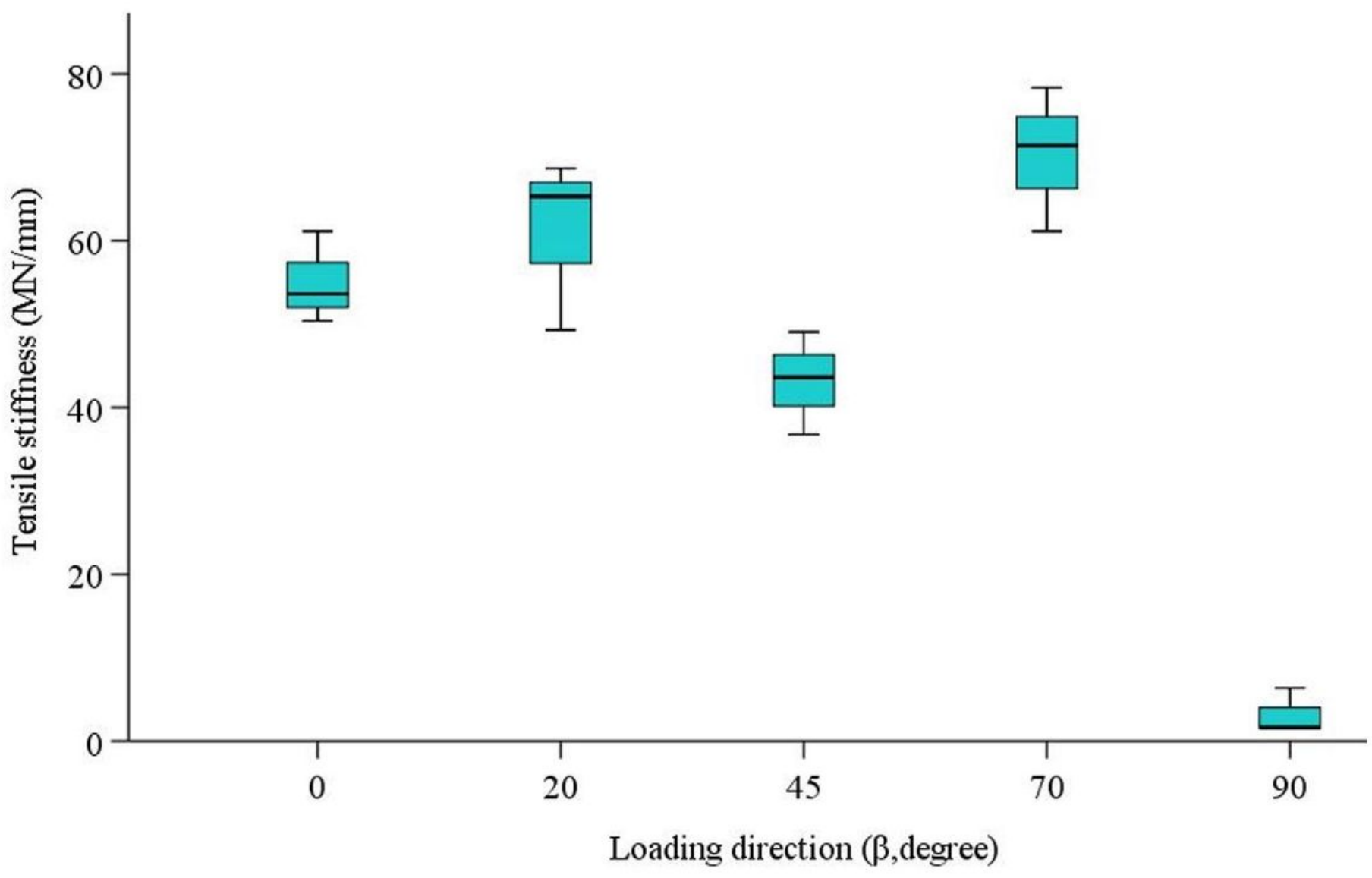

Figure 12

The effect of loading direction on tensile stiffness 

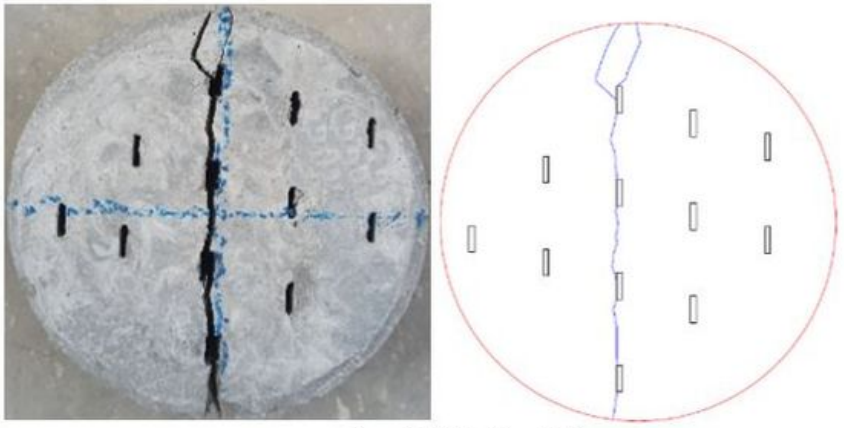

a) $\mathrm{B} 13, \beta=0^{\circ}$

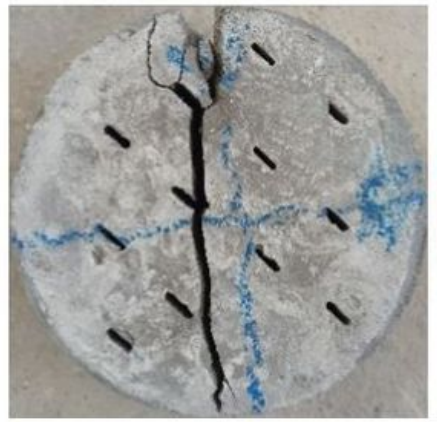

c) $\mathrm{B} 19, \beta=45^{\circ}$

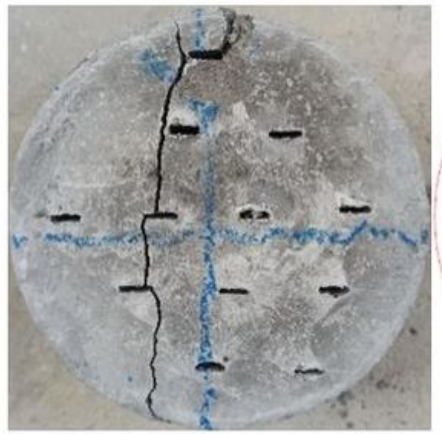

e) $\mathrm{B} 26, \beta=90^{\circ}$
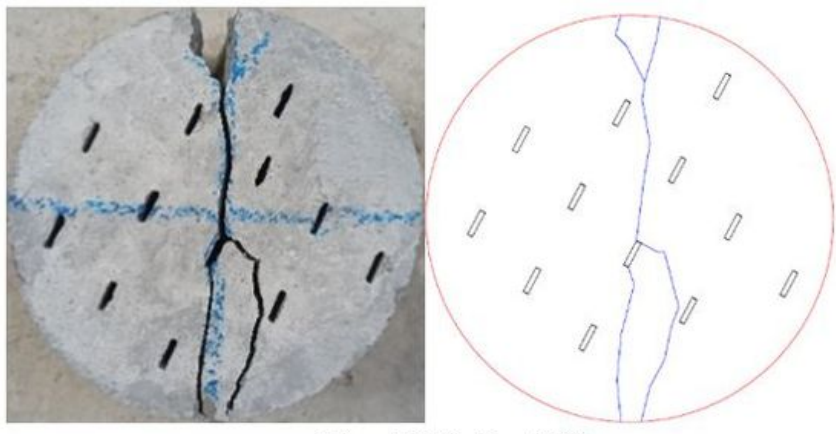

b) $\mathrm{B} 17, \beta=20^{\circ}$
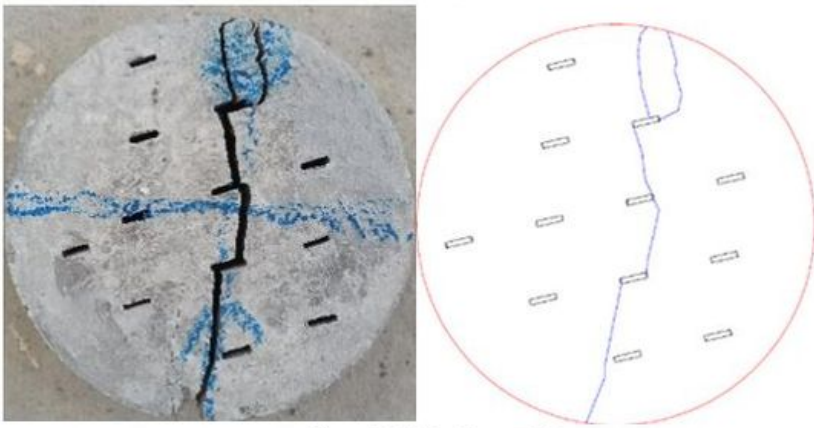

d) $B 22, \beta=70^{\circ}$

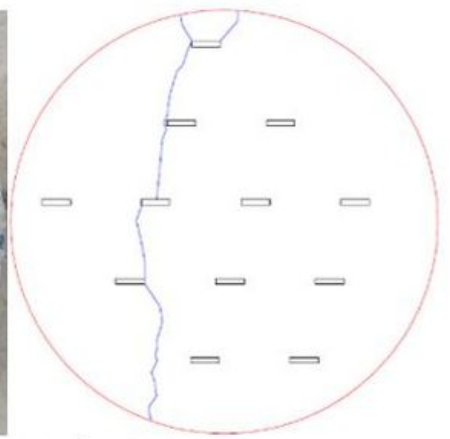

Figure 13

The effect of loading direction with respect to joint angle on failure pattern 


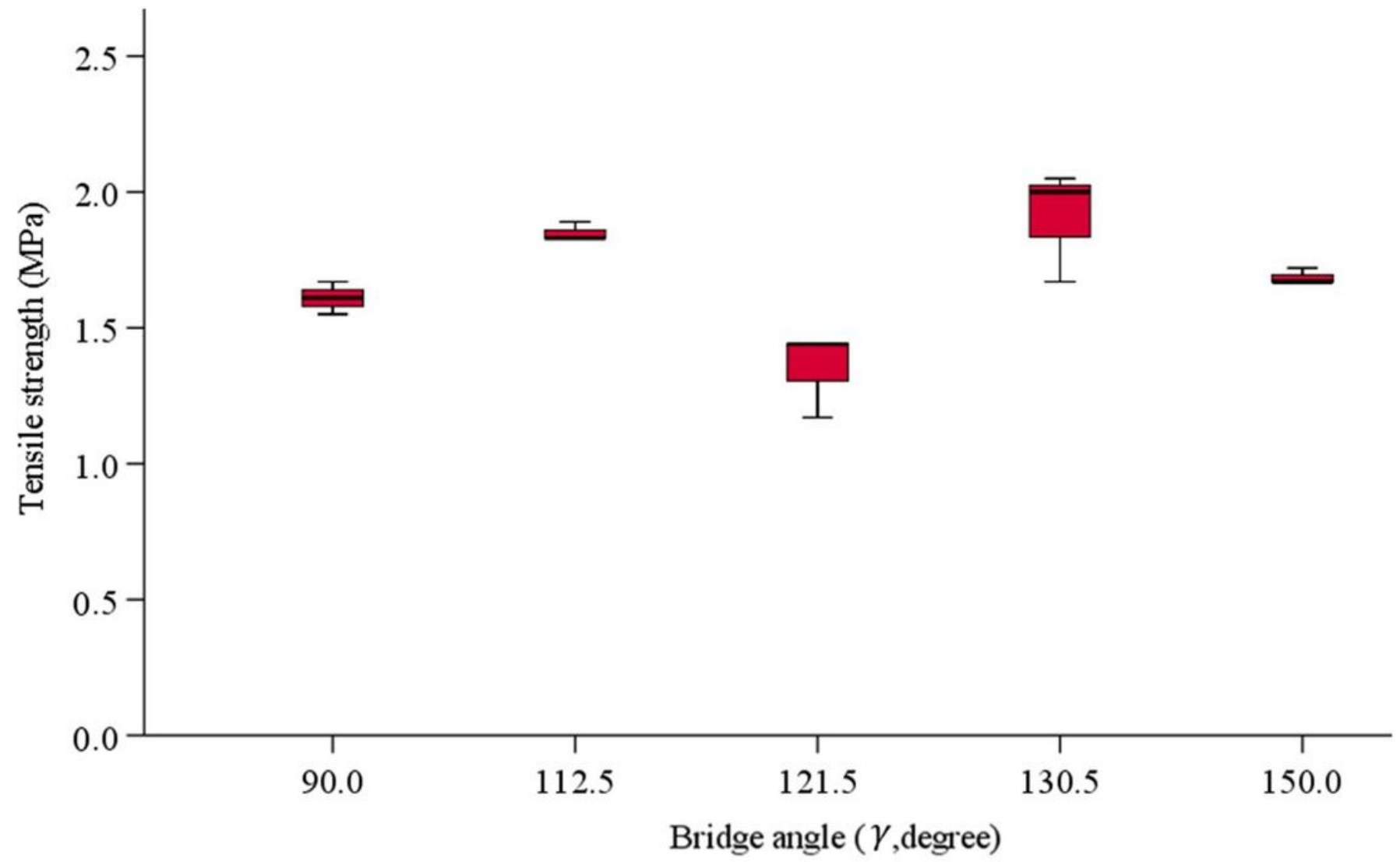

Figure 14

The effect of bridge angle on tensile strength

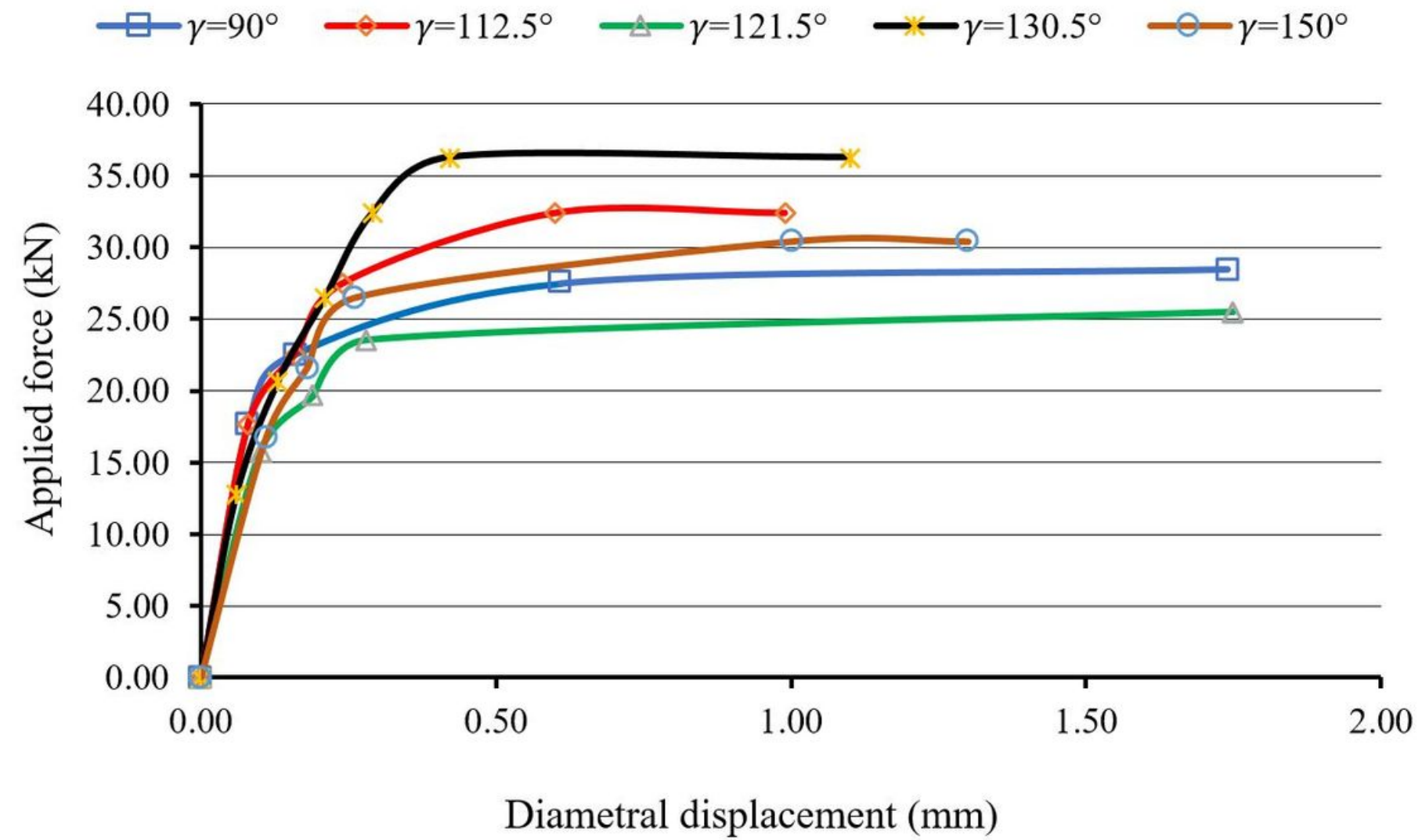

Page 20/26 
Figure 15

Force-displacement curve of samples with different $\gamma$

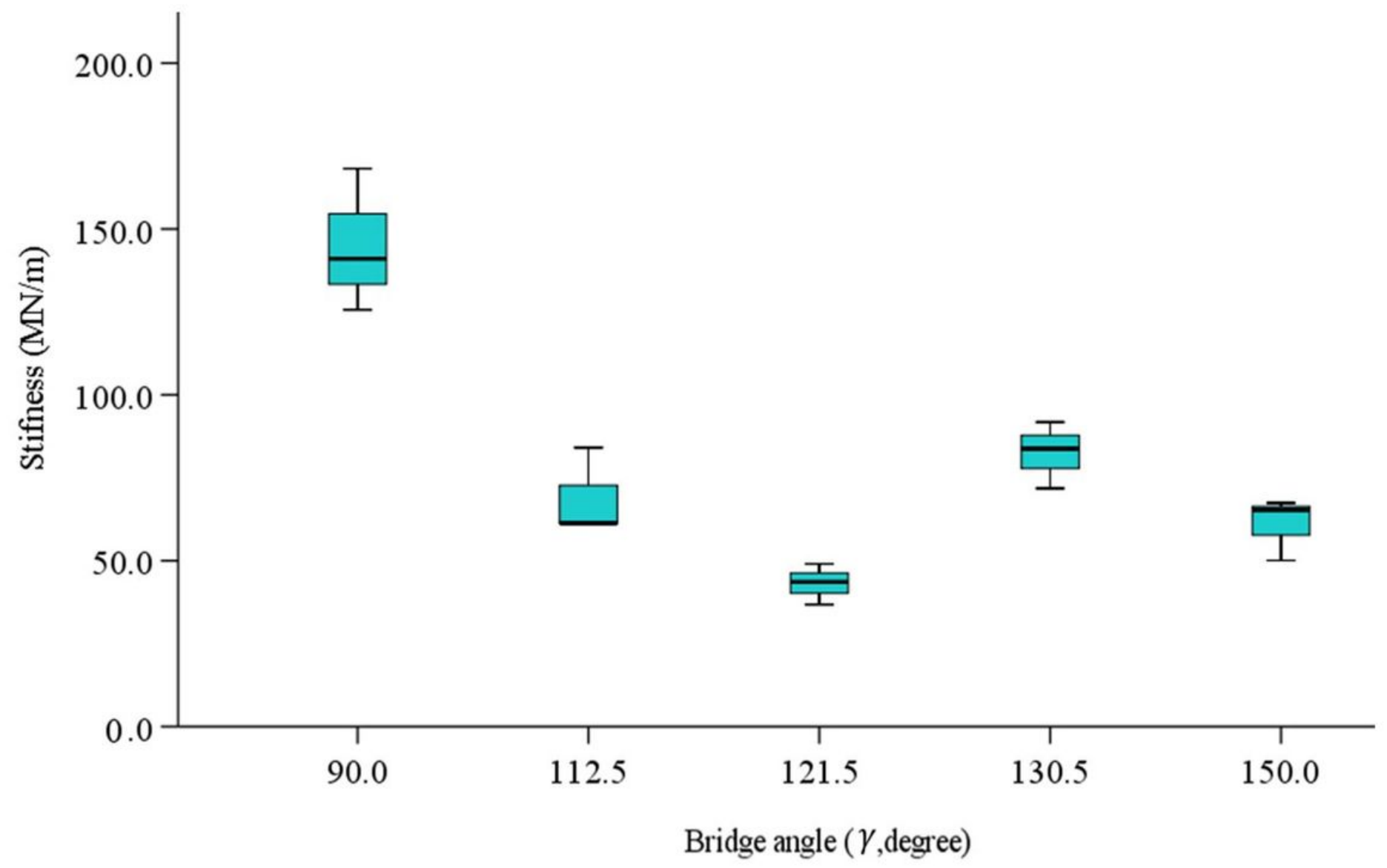

Figure 16

The effect of bridge angle on tensile stiffness 

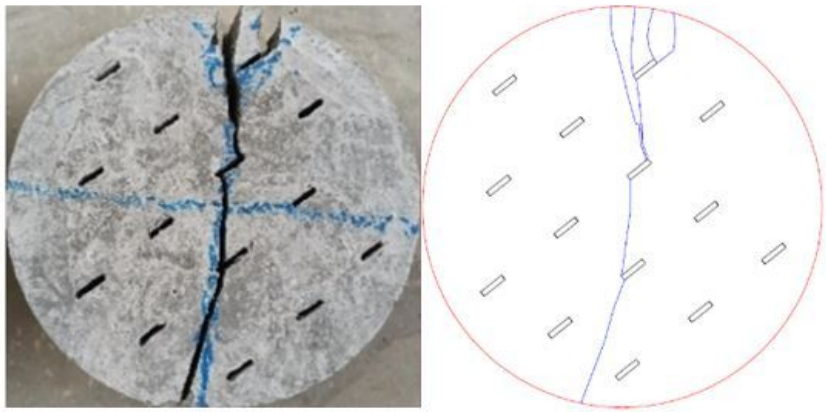

a) $\mathrm{B} 28, \gamma=90^{\circ}$
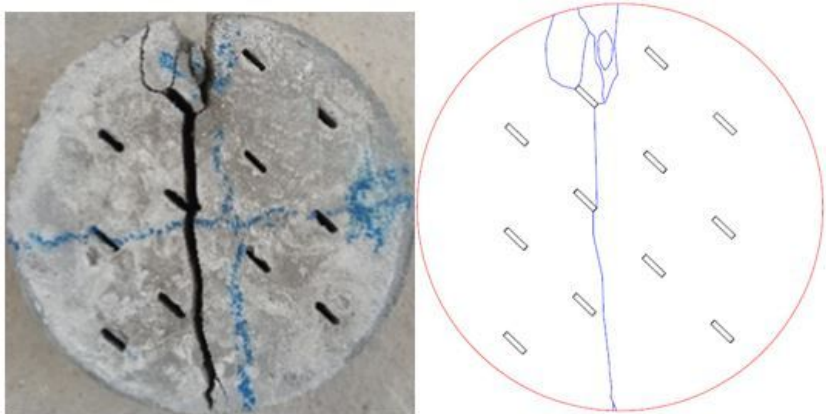

c) $\mathrm{B} 19, \gamma=121.5^{\circ}$

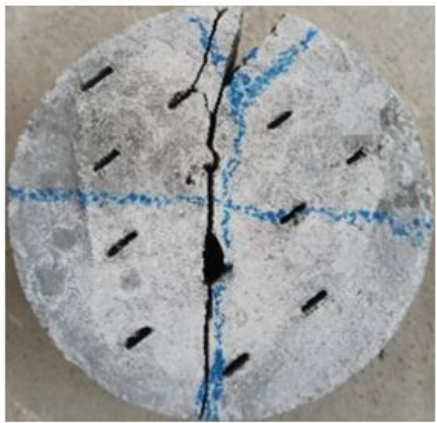

e) $\mathrm{B} 37, \gamma=150^{\circ}$
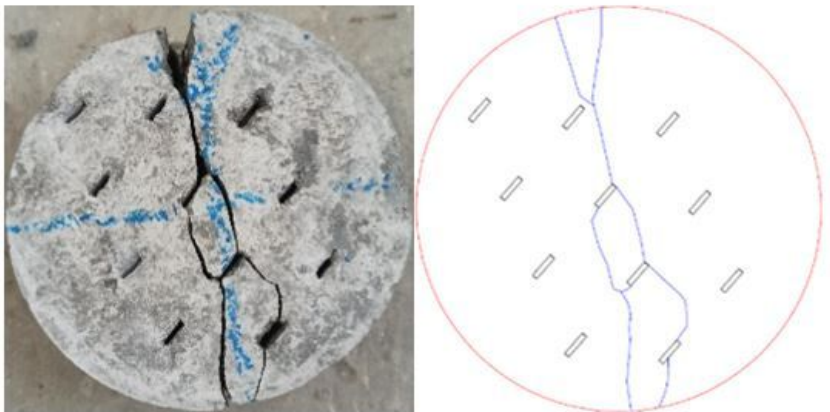

b) $\mathrm{B} 33, \gamma=112.5^{\circ}$
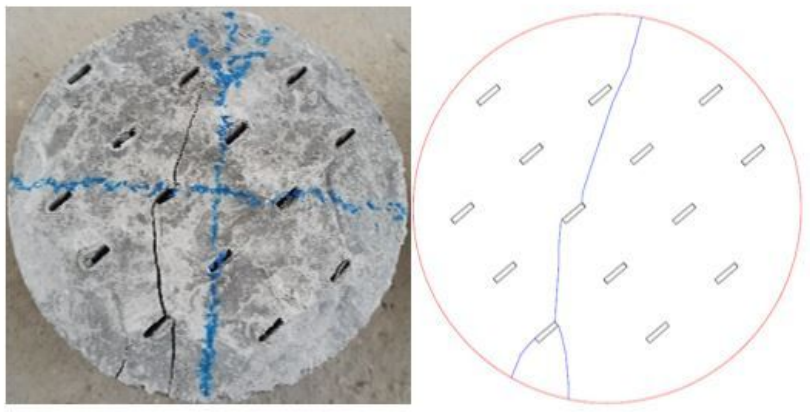

d) $\mathrm{B} 34, \gamma=130.5^{\circ}$

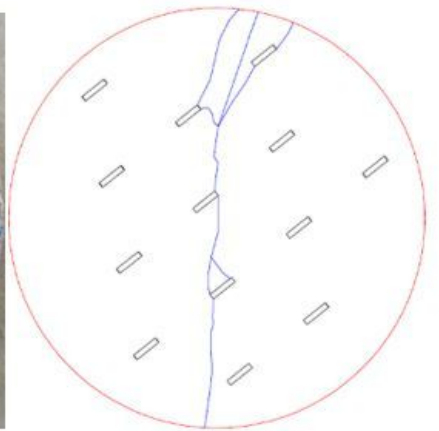

\section{Figure 17}

The effect of bridge angle on the samples' failure pattern 


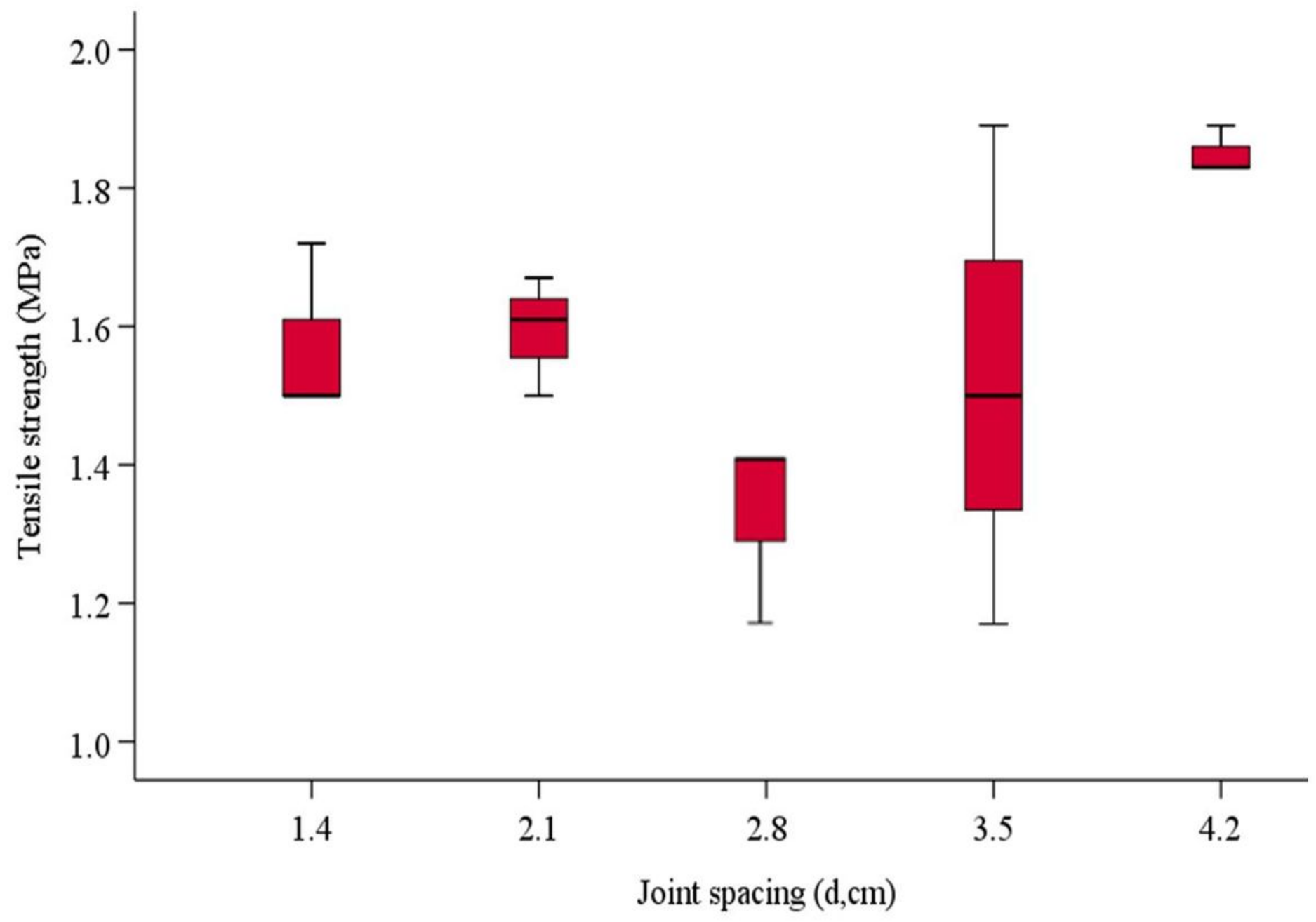

Figure 18

The effect of joint spacing on tensile strength 


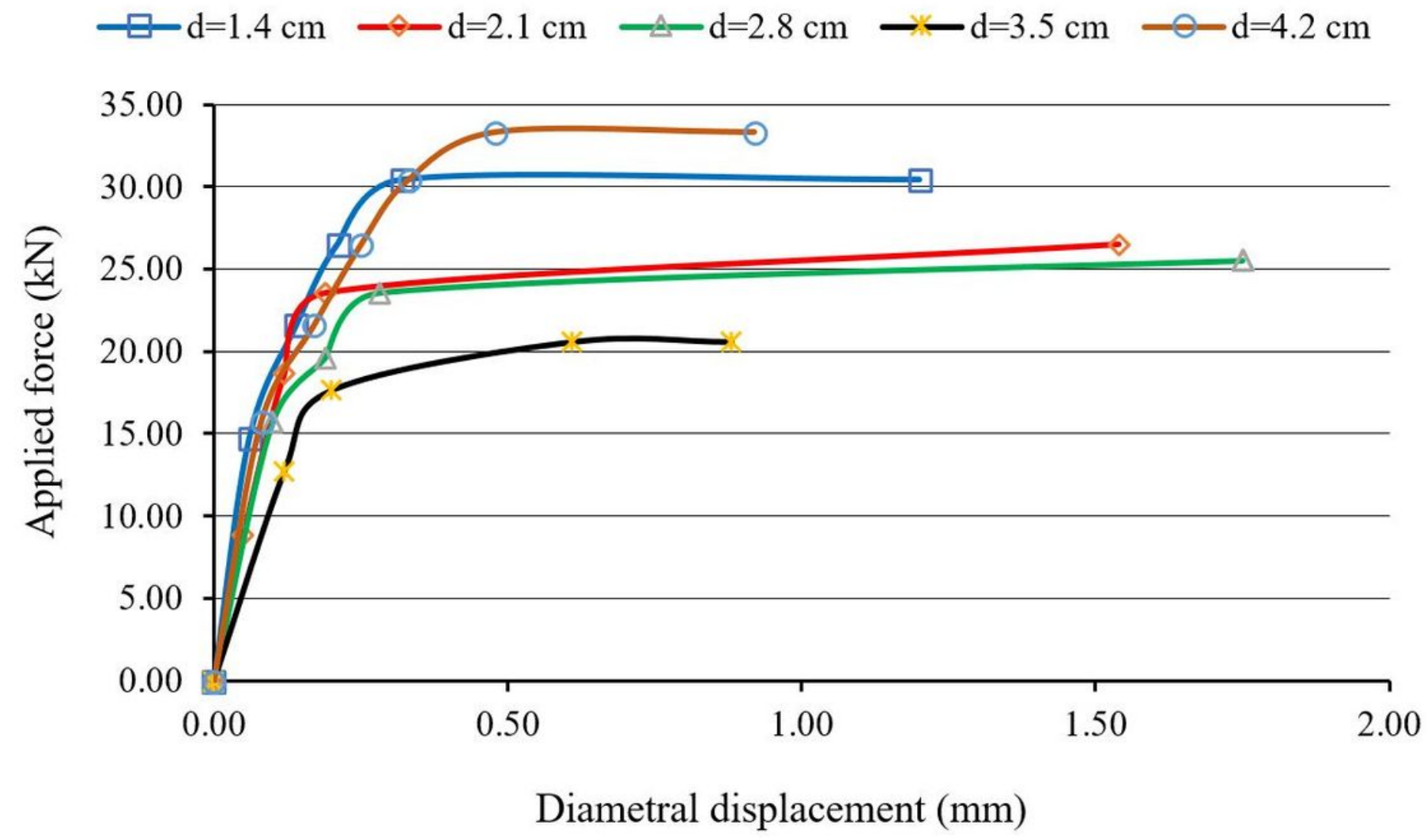

Figure 19

Force-displacement curve of samples with different d 


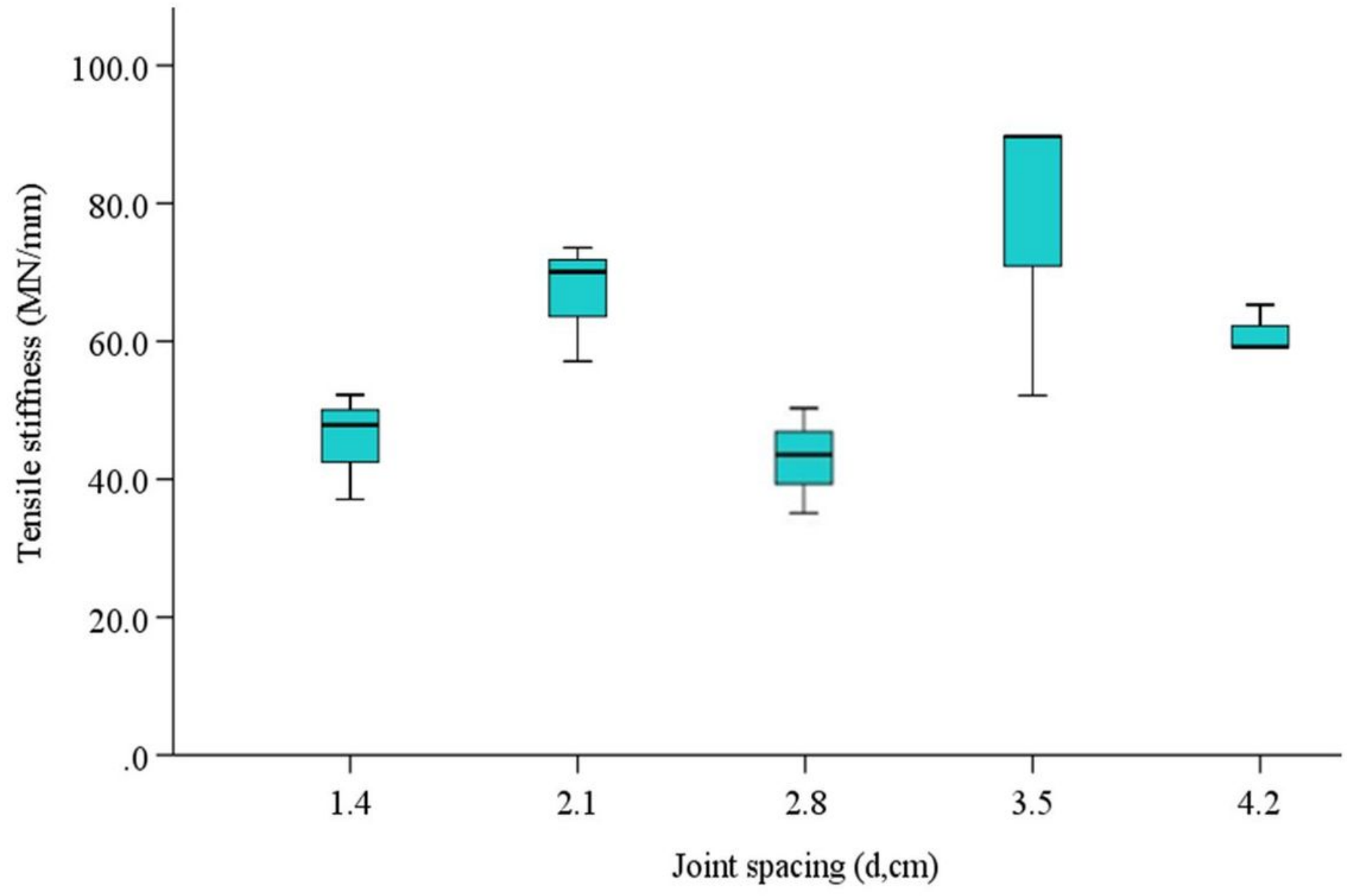

Figure 20

The effect of joint spacing on stiffness 


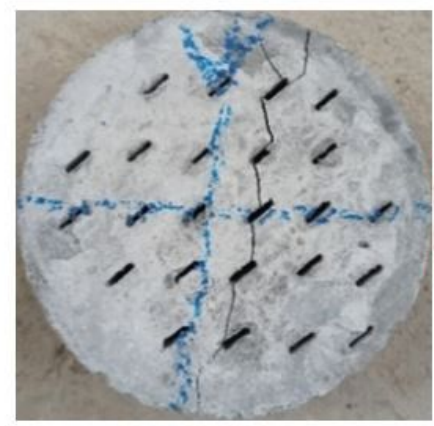

a) $B 40, d=1.4 \mathrm{~cm}$

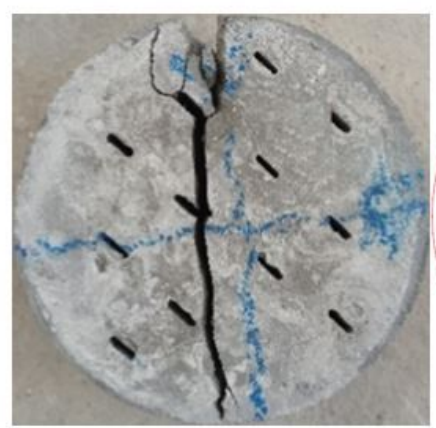

c) $B 19, \mathrm{~d}=2.8 \mathrm{~cm}$

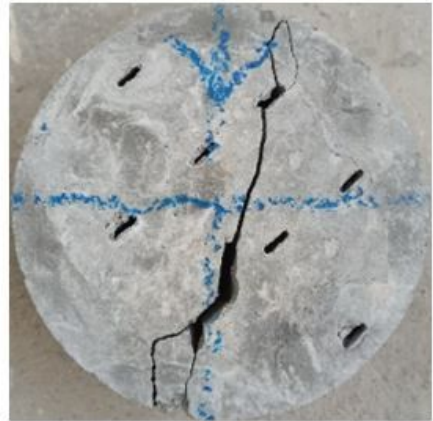

e) $B 49, d=4.2 \mathrm{~cm}$
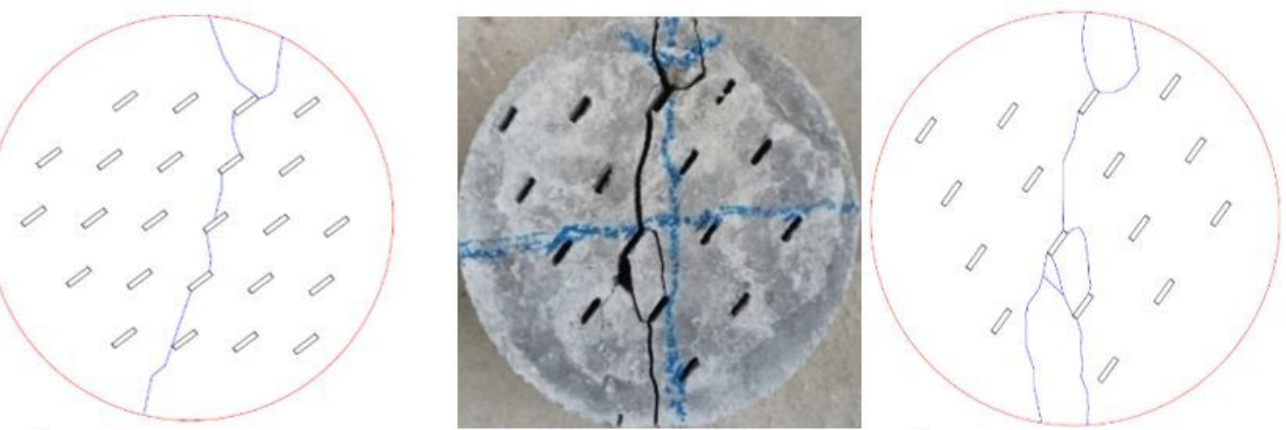

b) $B 43, d=2.1 \mathrm{~cm}$
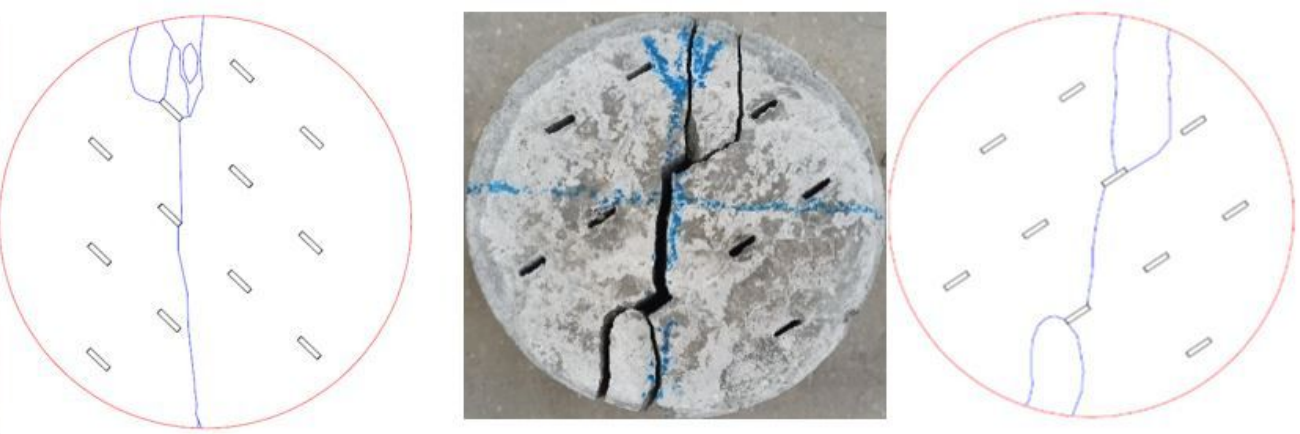

d) $B 47, d=3.5 \mathrm{~cm}$

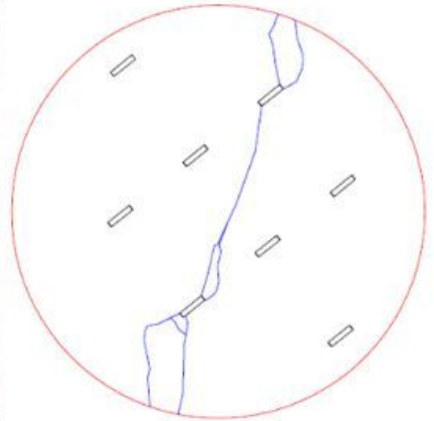

\section{Figure 21}

The effect of joint spacing on failure pattern 